\title{
Biocomposites Based on New Monomer Systems Reinforced with Micro / Nanoparticles and Glass Fibers
}

\author{
Cristina Prejmerean1, Tinca Buruiana², Teresa Nunes ${ }^{3}$, \\ Marioara Moldovan ${ }^{1}$ and Loredana Colceriu ${ }^{4}$ \\ "Babes-Bolyai University, "Raluca Ripan" \\ Institute of Research in Chemistry Cluj-Napoca \\ 2"Petru Poni" Institute of Macromolecular Chemistry Iasi \\ ${ }^{3}$ Centro de Química Estrutural, Complexo I, TU Lisbon \\ 4"Iuliu Hatieganu" University of Medicine and Pharmacy Cluj-Napoca \\ 1,2,4Romania \\ ${ }^{3}$ Portugal
}

\section{Introduction}

The resin composites were introduced for the first time in dentistry in the mid-1960s, for the restoration of anterior teeth, because of the necessity to eliminate the shortcomings of the restorative materials existing at that time. Because of their properties, aesthetic aspect, adhesion to hard dental tissues, high values of the physico-mechanical properties, they play an important role in dental practice (Bowen \& Marjenhoff, 1992).

Today, resin composite materials are frequently used for direct restoration of anterior teeth, as pit and fissure sealants for the prophylaxis of caries with children, and in prosthetic dentistry for the preparation of composite veneers, inlays and onlays by the photo-barrothermal polymerization. The composite veneers, inlays and onlays are fixed in the oral cavity using a luting agent, which is also a dual cured resin composite. The development of total polymeric restorations and the reinforcement of the resins with fibers for the obtaining of the prosthesis frameworks represent one of the actual achievements in the world.

The resin composites comprise three components: a) the resin matrix which consists of the monomer system, the initiator system for free radical polymerization, antioxidants and UV stabilizers, $b$ ) the inorganic filler consisting of particulates such as glass, quartz, and/or fused silica, or glass fibers, $c$ ) the coupling agent usually an organo-silane that chemically bonds the reinforcing filler to the resin matrix. When hardening is desired the polymerization of the monomers is initiated by a chemical or photochemical system. In the cured material, the inorganic filler particles are dispersed and chemically bonded in a crosslinked threedimensional network formed by the polymerization of the di(poly)functional monomers. The properties, and hence the performances of the materials are dependent upon the nature and features of the components of the material. In spite of the progress in dental composite technology, loss of anatomic form in time, marginal leakage due to polymerization 
shrinkage, contraction stresses generally concentrated at the adhesive interface leading to marginal debondings, as well as chromatic instability and water sorption, are often cited as being the main problems of resin composites (Peutzfeldt, 1997).

The resin composites routinely employed in dental practice have a resin matrix based on dimethacrylate monomers, which have been used for over 40 years. The main component in the most of the present commercial dental resins is still Bis-GMA (2,2-bis[4-(2-hydroxy-3methacryloxypropoxy)phenyl]propane, which was synthesized by Bowen in 1962 (Bowen, 1962). The reasons for its dominance are the positive properties, low volatility, fast hardening by radical polymerization, and relative low polymerization shrinkage. However, the main deficiencies of Bis-GMA are its high viscosity (1.0-1.2 $\mathrm{kPa}$.s at $\left.23^{\circ} \mathrm{C}\right)$, water sensitivity and low degree of conversion (Mozner \& Salz, 2001). A diluent, usually triethyleneglycol dimethacrylate TEGDMA, have to be added to reduce the viscosity of the resin. By adding TEGDMA to Bis-GMA, the water uptake and polymerization shrinkage and its associated stress of the cured material increase. The high viscosity and relatively high water sorption of Bis-GMA are due to the hydroxyl groups of its molecule. By converting the hydroxyl groups to other functional groups to avoid inter-molecular Hbonding thus minimizing viscosity, were obtained Bis-GMA substitutes, but they yield polymers with lower flexural strengths and modules (Holter et al., 1997). Most attention has been given to urethane derivatives of Bis-GMA, which exhibit lower viscosities, higher degree of vinyl conversion, and lower polymerization shrinkage at equivalent degrees of vinyl conversion than Bis-GMA (Moszner et al., 2008; Khatria et al., 2003; Pereira, et al., 2002).

Joining the research activities in the field, our studies have as the major objective to develop new resin composites with reduced polymerization shrinkage, high mechanical properties, decreased water sorption, chromatic stability and improved adhesion to tooth structure. The aim of the present work was to elaborate some particulate and fiber reinforced resin composites with new resin matrices and to investigate the influence of the resin composition upon the properties of the corresponding polymers and resin composite materials.

\section{Materials and methods}

\subsection{The elaboration and characterization of a series of new experimental resins}

The new experimental resins are formulated using mixtures of Bis-GMA type superior oligomers with high molecular weight (Prejmerean et al. 2000) and Bis-GMA analogues obtained by the addition of some blocking structures (e.g. methacryloyloxyethyl isocyanate) to the Bis-GMA glycidyl hydroxyl groups (Buruiana et al., 2008).

The formula for Bis-GMA0, Bis-GMA1, Bis-GMA2 and Bis-GMA3 are presented below:

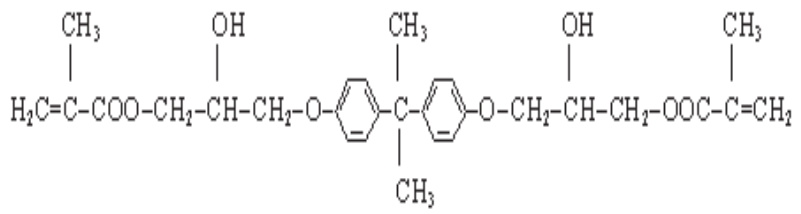

2,2-bis[4-(2-hydroxy-3-methacryloxypropoxy) phenyl]propane Bis-GMA0 (commercial) 


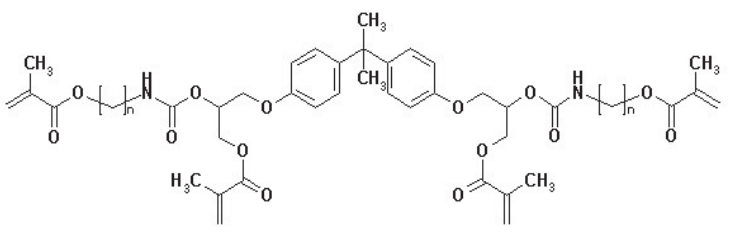

Bis-GMA1 $(\mathrm{n}=2)$

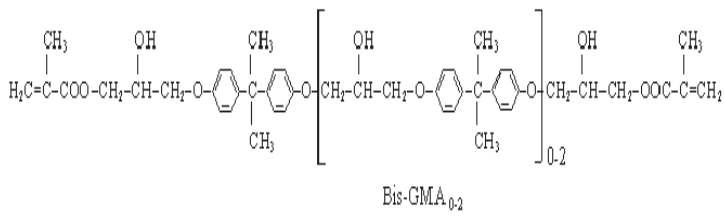

Bis-GMA2

(mixture of oligomers : $81 \%$ monomer, $17 \%$ dimer and $1 \%$ trimer)<smiles>C=C(C)C(=O)OCC(COc1ccc(C(C)(C)c2ccc(OCC(COC(=O)C(=C)C)OC(C)(C)C(C)(C)CO)cc2)cc1)OC(C)(C)C(C)(C)C</smiles>

Fig. 1. The experimental monomers used in the study

\subsection{The preparation of the copolymers by chemical initiation of polymerization}

In order to obtain the copolymers by chemical initiation of polymerization, two monomer mixtures were prepared for each copolymer (two resins), which had the same monomer amount, as presented in table 1: resins A and B. In resins A was dissolved $2 \%$ by weight of the polymerization accelerator (N,N-dihydroxyethyl-p-toluidine, DHEPT) and in resins B, was added $2 \%$ by weight of the polymerization initiator, benzoyl peroxide (POB). Butylated hydroxytoluene (BHT) was used as an inhibitor in an amount of $0.1 \%$ by weight. The copolymers were obtain by mixing equal amounts of A resins with corresponding B resins. The polymerization took place under a polyethylene band in order to prevent the contact with the atmospheric oxygen. The obtained copolymers were ground to fine powders.

\subsection{The preparation of the copolymers by photochemical initiation of polymerization}

Using the photochemical polymerization system of monomer mixtures presented in table 1, some copolymers were prepared. In the composition of the monomer mixtures, besides the methacrylic oligomers and monomers, a photosensitizer, camphorquinone (CQ) in an amount of $0.5 \%$ (by weight), and an accelerator dimethylaminoethyl-methacrylate (DMAEM), in an amount of $1 \%$ (by weight), were added. BHT was added in a quantity of $650 \mathrm{ppm}$ related to the monomer mixture. The mixtures were hardened by exposing to a visible radiation in the wavelength range of $400-500 \mathrm{~nm}$, for 30 seconds. The radiation was 
generated by an Optilux stomatological lamp ( $14 \mathrm{~V}$ and $35 \mathrm{~W})$, produced by Demetron Research Corporation USA. The copolymers were ground to fine powders.

\subsection{Determination of the residual double bonds}

The conversion of monomer mixtures was evaluated by determining the residual double bonds using the Infrared Spectroscopy Method. The quantity of unreacted methacrylate groups is determined in percent of the methacrylate groups originally present in the unpolymerized material. The decrease in the intensity of the methacrylate $\mathrm{C}=\mathrm{C}$ absorbance $\left(\mathrm{A}_{\text {meth }}\right)$ at $1635-1640 \mathrm{~cm}^{-1}$ was monitored. The phenyl absorbance $\left(\mathrm{A}_{\text {arom }}\right)$ at $1605-1610 \mathrm{~cm}^{-1}$ was used as an internal standard (Ruyter \& Gyorosi, 1978).

The FTIR spectra of the liquid monomers mixtures prepared as liquid thin films between $\mathrm{KBr}$ plates and of the solid corresponding copolymers prepared as $\mathrm{KBr}$ pellets were recorded on a JASCO 610 FTIR Spectrophotometer.

\subsection{Determination of volumetric polymerization contraction}

Polymerization shrinkage was determined using the analysis of the network by stray-field MRI.

One-dimensional ${ }^{1} \mathrm{H}$ STRAFI images, projections along an axis, were acquired from the liquid and from the photopolymerized monomers using a Bruker MSL 300P spectrometer, under the static magnetic field gradient of $37.5 \mathrm{~T} / \mathrm{m}$ generated near the edges of the $89 \mathrm{~mm}$ superconducting coil. A dedicated Bruker STRAFI probe-head was tuned to $123.4 \mathrm{MHz}$, which gives ${ }^{1} \mathrm{H}$ resonances at $2.9 \mathrm{~T}$; this field strength was obtained just outside the bore of the magnet. Since only thin slices are observed at a time, 1D imaging of bulk specimens was conducted by moving the sample linearly in the direction of the field gradient to ensure that the volume under analysis experiences the same field conditions. Each liquid sample was introduced in a cylindrical glass vial ( $5 \mathrm{~mm}$ height and $6 \mathrm{~mm}$ inner diameter) filled up to 4 $\mathrm{mm}$ height. In order to obtain VPC, magnetization profiles were acquired prior irradiation (Optilux 401, Demetron Research Corp., Danbury, CT, USA) and after the irradiation period

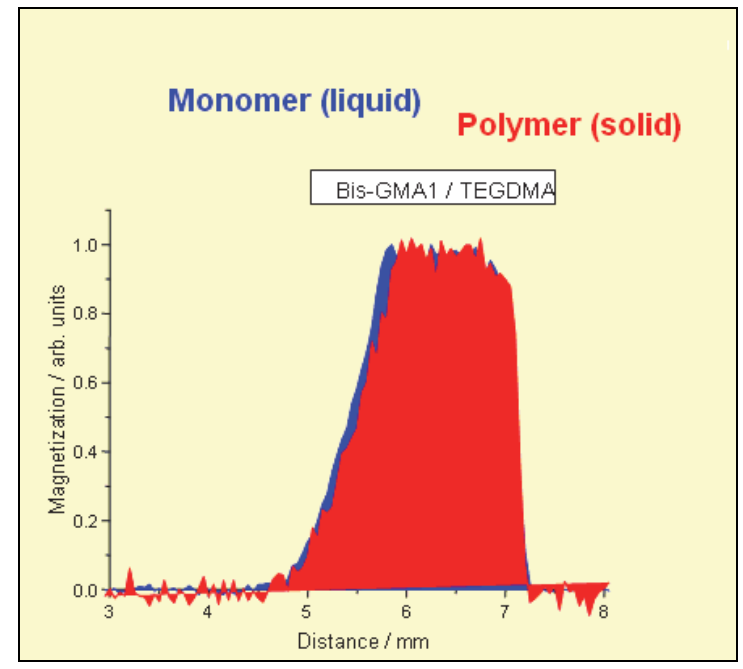

Fig. 2. Schematic representation of volumetric polymerization shrinkage 
of $10 \mathrm{~s}\left(500 \mathrm{~mW} / \mathrm{cm}^{2}\right)$. The photopolymerization was carried out at room temperature (about $22{ }^{\circ} \mathrm{C}$ ). The magnetization was recorded as multiple 8 spin-echo trains. Each echo train was generated by the RF pulse sequence $90^{\circ} x-\tau-\left[90^{\circ} \text { - } \tau \text {-echo- } \tau\right]_{8}$, where $90^{\circ}$,y represents a $90^{\circ}$ pulse of relative phase $\mathrm{x}$ or $\mathrm{y}$ and $\tau$ is a short time delay; the RF pulse duration $\left(t_{p}\right)$ and echo time (TE) were $10 \mu \mathrm{s}$ and $35 \mu \mathrm{s}$, respectively (Nunes et al., 2002). Each data slice in the STRAFI profiles is the result of the summation of the 8 echoes.

The final volumetric polymerization shrinkage (VPC, in \%) was determined for all monomers, according to a method previously described (Pereira et al., 2002; Nunes et al., 2005), as:

$$
\mathrm{VPC}=[\Sigma(\mathrm{MM})-\Sigma(\mathrm{MP}) \times 100] / \Sigma(\mathrm{MM})
$$

where MM and MP represent the magnetisation of each slice of the comonomer mixture and of the system cured over $10 \mathrm{~s}$ at about $500 \mathrm{~mW} / \mathrm{cm}^{2}$, respectively; the highest intensity of $\mathrm{MP}$ was used as a reference for the intensity normalization of the magnetisation of MM and MP slices.

\subsection{Determination of leachable components from experimental dental copolymers}

The method of evaluating the quantities of residual monomer and of residual light stabilizer respectively, proposed in the present study is based on the accelerated extraction of the eluted components from the copolymers in chloroform, at the boiling temperature of chloroform, for ten hours. The residual monomer and residual light stabilizer amounts have been determined from the UV spectra of the chloroformic extracts as percent of the monomer (stabilizer) originally present in the unpolymerised materials. The experimental copolymers were transformed into fine powders and $0.5 \mathrm{~g}$ of powder was extracted into 100 $\mathrm{ml}$ chloroform.

\subsection{Obtaining of the experimental light-curing composites}

The experimental light-curing composites were prepared as monopastes from the resin matrices and the hybrid filler. The monomer mixtures in the light-curing composites consist of Bis-GMA-type monomer and TEGDMA. The inorganic phase consisted of $90 \%$ silanized barium glass $\left(45 \% \mathrm{SiO}_{2}, 10 \% \mathrm{Al}_{2} \mathrm{O}_{3}, 17 \% \mathrm{~B}_{2} \mathrm{O}_{3}, 20 \% \mathrm{BaO}, 8 \% \mathrm{NaF}_{-} \mathrm{CaF}_{2}\right)$ and $10 \%$ silanized colloidal silica. The powder/liquid ratio was $4 / 1$. The light-curing resin composites were cured by exposing to a visible radiation in the wavelength range of $400-500 \mathrm{~nm}$ for 40 seconds.

\subsection{Determination of mechanical properties}

\subsubsection{Determination of compressive strength}

The compressive strength (CS) was determined using specimens having cylindrical shape with $8 \mathrm{~mm}$ height and $4 \mathrm{~mm}$ diameter. The specimens were illuminated in their respective molds by the light source (OPTILUX dental lamp, Demetron Research Corporation, USA) in steps of $2 \mathrm{~mm}$ height, for 40 seconds each step. The measurements of the compressive strength were made using a Lloyd LR5K Plus mechanical testing apparatus at a 0.5 $\mathrm{mm} / \mathrm{min}$ pressing speed. The compression strength CS (in $\mathrm{MPa}$ ) was calculated applying formula (2) where $\mathrm{F}$ is the maximum applied load $(\mathrm{N})$ and $\mathrm{d}$ is the specimen diameter $(\mathrm{mm})$.

$$
C S=F / 0.785 d^{2}
$$




\subsubsection{Determination of diametral tensile strength}

The tensile strength was measured using the diametral compression test (the indirect test of determining the tensile strength). The general technique of preparing and testing the composites specimens was similar to the one described when determining the compression strength, with the only difference that the cylindrical specimens had $4 \mathrm{~mm}$ thickness $(\mathrm{T})$ and $6 \mathrm{~mm}$ in diameter (D). The specimens were subjected to compression along the cylinder generator. The F force that acts on the cylinder, caught between the pans of the apparatus, determines the appearance of the tensile efforts on the vertical diameter plane. The tensile strength DTS (in MPa) was calculated applying the formula (3):

$$
D T S=2 \times F / \pi \times D \times T
$$

\subsubsection{Determination of flexural strength}

The flexural strength was determined using specimens having rectangular form (length 25.0 $\mathrm{mm}$, height $2.0 \mathrm{~mm}$ and width $2.0 \mathrm{~mm}$ ), according to ISO 4049/2000. The general technique of preparing the composite specimens was similar with the one used at the determination of compressive strength. After the measurement of height $a$ and width $b$, the specimens were subjected to three-point loading with $l=20 \mathrm{~mm}$ between the supports. The crosshead speed of the testing machine was $1.0 \mathrm{~mm} / \mathrm{min}$. The flexural strengths FS were calculated as:

$$
F S=2 \times F \times l / 2 \times b \times a^{2}
$$

\subsection{Determination of color changes of the stabilized composites}

In order to evaluate the color changes of the composites, the samples in form of disks (30 $\mathrm{mm}$ diameter $\times 2 \mathrm{~mm}$ thick) have been exposed to UV radiation (Narva lamp- $\mathrm{HgE} / 2$ $(\lambda=250-450 \mathrm{~nm}))$. The light source used a mercury vapor lamp at high pressure. The samples were stored in water at $37^{\circ} \mathrm{C}$. After water storage, the specimens were placed on a Unicam 4 UV-VIS spectrometer. The coordinates $\left(\Delta \mathbf{a}^{*}, \Delta \mathbf{b}^{*} \Delta \mathbf{L}^{*}\right)$ of reflection spectrum were recorded and the color differences $\Delta \mathrm{E}^{*}$ in cielab system were calculated by formula:

$$
\Delta E^{*}=\left(\Delta L^{* 2}+\Delta a^{*}+\Delta b^{* 2}\right)^{1 / 2}
$$

$\Delta \mathrm{L}^{*}$ means the difference of luminosity between initial and final samples; $\Delta \mathrm{a}^{*}$ means the difference between the "red-green" coloured coordinates of the initial and final sample; $\Delta \mathrm{b}^{*}$ means the differece between the "yellow-green" colored coordinates of the initial and final sample. Spectra were recorded after 1, 7 and 30 days exposure to the ultraviolet light source. The coordinates $\left(\Delta \mathbf{a}^{*}, \Delta \mathbf{b}^{*} \Delta \mathbf{L}^{*}\right)$ were determined also by analyzing the digital images of the initial and final samples using a specific software.

\subsection{Determination of water sorption}

Disk specimens of composites $15 \pm 1 \mathrm{~mm}$ diameter and $1 \pm 0.1 \mathrm{~mm}$ thickness were prepared in a mold by exposing each side to a visible radiation in the range of 400-500 nm for $40 \mathrm{sec}$ using a dental lamp.

Water sorption values were determined according to ISO 4049/2000 at 7 days of storage in water. The values for water sorption (Wsp), for each of the specimens were calculated using the formula:

$$
W s p=M 1-M 2 / V
$$


M1 - the mass of the specimen after immersion in water $[\mu \mathrm{g}]$,

M2 - the mass of the reconditioned specimen $[\mu \mathrm{g}]$,

$\mathrm{V}$ - volume of the specimen $\left[\mathrm{mm}^{3}\right]$

\subsection{Investigation of adhesion of the resin composites to dental tissues}

For this purpose were used 24 human premolar teeth in which two class $\mathrm{V}$ cavities $(3 \mathrm{~mm} \mathrm{x}$ $4 \mathrm{~mm} \times 1.5 \mathrm{~mm}$ ) were prepared on facial and oral surfaces with a cervical margin in cementum (dentin). Resin composites with or without previous use of an adhesive were applied to the cavities. The teeth were sectioned on an Isomet Low Speed Saw-Buechler LTD machine. SEM (FEI Comp) photomicrographs of the interfacial region between tooth and resin composites were performed.

\section{Results and discussion}

\subsection{Determination of residual double bonds (RDB) in copolymer matrices}

A crosslinked three-dimensional network is formed by the polymerization of the monomer mixtures existing in the dental diacrylic resins. During the polymerization of dimethacrylate monomers, the gel effect occurs, leading to the closing of radicals and unreacted monomers in the crosslinked network. The commercial diacrylic resins, investigated in the literature have between 25 and 50\% unreacted methacrylate groups, where a tenth part of them represents the residual monomer (Asmussen, 1982; Ferracane, 1994). Presence of residual monomer or unreacted double bonds in the harden matrix has a plasticizing effect on the polymer. More than that, residual double bonds can make the polymeric matrix more susceptible to degradative reactions (Grassie, 1966).

Composition of the experimental monomer mixtures and the quantity of residual double bonds of the corresponding dental copolymers are presented in table 1 . The quantity of residual double bonds remained unreacted after the chemical and respectively photochemical polymerization, as a percent of the total quantity of double bonds existing before the polymerization (RDB\%) of the experimental BisGMA-type base monomers/TEGDMA mixtures were shown. It can be noticed an increasing of RDB with the increasing of the content of Bis-GMA type monomer, hence to the decreasing of TEGDMA monomer, both for the chemically and photochemically polymerized mixtures. The value of RDB ranged between $34.12 \%$ and $47.12 \%$ in the case of chemically polymerized mixtures, and between $30.40 \%$ and $46.39 \%$ in the case of photochemical polymerization, for Bis-GMA. type monomer/TEGDMA ratios between 50/50 and 75/25.

The increasing of RDB percent with the increasing of the Bis-GMA-type monomer/TEGDMA ratio can be explained by the effect of physical-chemical characteristics of the mixtures upon the evolution of polymerization reaction. The mixtures with a high Bis-GMA-type monomer/TEGDMA ratio, characterized by a high viscosity because of the large rigid molecules with reduced mobility of Bis-GMA-type monomers, reach the gel state in a short time after the beginning of reaction. After their polymerization, a large number of double bonds remain unreacted, as pendant double bonds and as residual monomer respectively.

The more advanced conversion (lower percent of RDB) obtained in the case of the photochemical polymerization than in the case of chemical polymerization of monomer mixtures, for the same Bis-GMA-type monomer/TEGDMA ratios can be explained by the relatively fast release of polymerization initiating radicals in the light cured materials.

Comparing the monomer mixtures that differ by the nature of the Bis-GMA type monomer and have the same ratio between the Bis-GMA-type monomer and TEGDMA, one can 
observe that the lowest percent of residual double bonds are registered in the case of polymerization the Bis-GMA0-based mixture, followed in order by Bis-GMA1-based mixture, Bis-GMA3- based resin and Bis-GMA2-based resin. Comparing the monomer mixtures containing Bis-GMA0 and Bis-GMA1, it can be noticed that Bis-GMA1-based mixtures lead to a slight increase of the quantity of RDB. This behaviour can be explained by the fact that Bis-GMA1 molecule contain four methacrylic bonds comparing to two methacrylic bonds contained by Bis-GMA0, so after polymerization remains a greater number of RDB in the case of Bis-GMA1-based mixtures. Replacing of the Bis-GMA0 monomer with Bis-GMA2 monomer produces mixtures with increased viscosities, the existence of larger molecules with less mobility belonging to the dimer and trimer from BisGMA2 leads finally to achieve the gel state at lower times, and to a larger number of unreacted double bonds. Bis-GMA3 shows conversions of double bonds between the values obtained for Bis-GMA1 and Bis-GMA2.

\begin{tabular}{|c|c|c|c|c|c|c|c|}
\hline No. & $\begin{array}{c}\text { Bis-GMA } \\
\%\end{array}$ & $\begin{array}{c}\text { Bis-GMA1 } \\
\%\end{array}$ & $\begin{array}{c}\text { Bis-GMA2 } \\
\%\end{array}$ & $\begin{array}{c}\text { Bis-GMA3 } \\
\%\end{array}$ & $\begin{array}{c}\text { TEGDMA } \\
\%\end{array}$ & $\begin{array}{c}\text { RDB \% } \\
\text { Chemical } \\
\text { initiation }\end{array}$ & $\begin{array}{c}\text { RDB \% } \\
\text { Photo- } \\
\text { chemical } \\
\text { initiation }\end{array}$ \\
\hline R1. & 75 & - & - & - & 25 & 37.25 & 36.89 \\
\hline R2. & 60 & - & - & - & 40 & 36.89 & 32.18 \\
\hline R3. & 50 & - & - & - & 50 & 34.75 & 30.40 \\
\hline R7. & - & 75 & & - & 25 & 40.37 & 37.33 \\
\hline R8. & - & 60 & & - & 40 & 38.43 & 35.2 \\
\hline R9. & - & 50 & & - & 50 & 34.12 & 32.11 \\
\hline R4. & - & & 75 & - & 25 & 47.12 & 46.39 \\
\hline R5. & - & & 60 & - & 40 & 41.30 & 38.21 \\
\hline R6. & - & & 50 & - & 50 & 38.53 & 35.53 \\
\hline R10 & - & - & - & 75 & 25 & 43.76 & 42.11 \\
\hline R11. & - & - & - & 60 & 40 & 40.11 & 39.90 \\
\hline R12 & - & - & - & 50 & 50 & 37.12 & 36.17 \\
\hline
\end{tabular}

Table 1. Composition of the monomer mixtures and the quantity of residual double bonds (RDB) of the corresponding copolymers

\subsection{Determination of polymerization shrinkage}

Resins and composite resins shrink during polymerization, mainly because the monomeric units of the polymer are then located within covalent bond distance of each other, that is, closer to one another than they were in the original monomer state. In fact, two van der Waals distances and one double bond are converted into two single bonds when a radical reacts with a methacrylate group; overall a total of about $3.74 \AA$ is shortened to about $3.08 \AA$. Therefore, polymerization reaction induces necessarily a volumetric shrinkage (VPC) of the monomer mixture. Clearly, a high degree of conversion determines a strong VPC and the best compromise must be found in order to obtain dental materials with optimum performance. Particularly for the monomer-based materials, unreacted monomers remain in the final product, which is mostly the case of surface layers in contact with atmospheric molecular oxygen, a well-known-radical scavenger. ${ }^{1} \mathrm{H}$ STRAFI enables measuring the volumetric contraction in non-invasive and non-destructive modes, in the presence of oxygen from the atmosphere; in the case of dental adhesives VPC is due to solvent evaporation and photopolymerization shrinkage (Nunes et al., 2005). 
The polymerization shrinkage of the experimental new resins is presented. The resins contain 75\% Bis-GMA type monomer (Bis-GMA0, Bis-GMA1, Bis-GMA2 and Bis-GMA3) and 25\% TEGDMA. Figure 3 shows profiles of monomer mixtures (prior irradiation) and of monomer mixtures photopolymerized over $10 \mathrm{~s}$ at $500 \mathrm{~mW} / \mathrm{cm}^{2}$. It must be noticed that in this figure the profiles are rotated of 90 degrees and, consequently, the sample surfaces are shown on the left-side of the plots. The first general observation is the narrowing of the profiles after exposure to light. This effect is clearly associated with contractions during polymerization and hence overall volume reduction. Table 2 presents VPC data obtained for the indicated comonomer mixtures; these values show that the resin based on Bis-GMA1 monomer has a polymerization shrinkage that represents $2 / 3$ of the value presented by BisGMA0-based resin. The evolution of curing was locally monitored by the changes observed to the ${ }^{1} \mathrm{H}$ magnetization signal intensity, which depend on hydrogen concentration but are strongly weighted essentially by proton mobility in the $\mathrm{kHz}$ frequency range. Therefore, intensity variations can be directly related to volumetric contractions (Nunes et al., 2001).

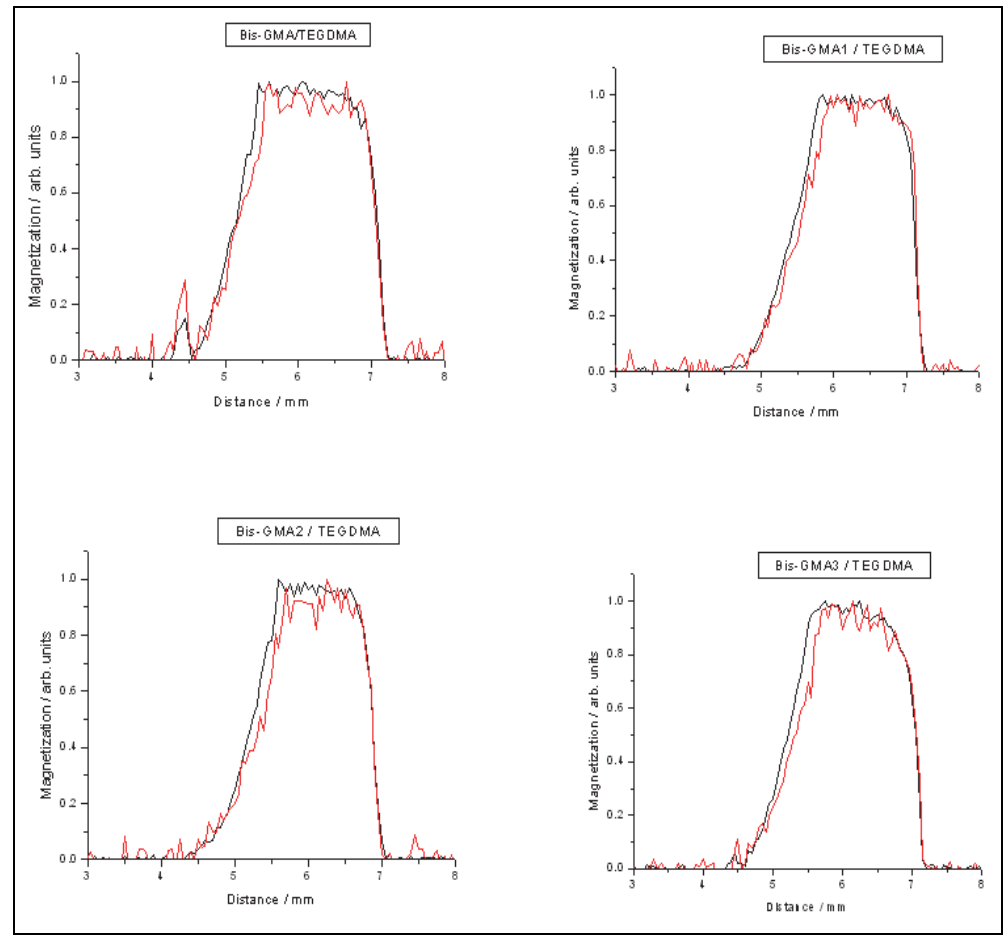

Fig. 3. Profiles of monomer mixtures (black line) and photopolymerized monomer mixtures over $10 \mathrm{~s}$ at $500 \mathrm{~mW} / \mathrm{cm}^{2}$ (red line); normalization was based on the assignment of $1 \mathrm{arb}$. unit to the highest magnetisation intensity obtained from both profiles.

Monomers with shorter molecular length (with identical functionality, hence with a high concentration of double bonds) are expected to react faster; in addition, monomers of higher flexibility (lower $\mathrm{T}_{\mathrm{g}}$ ) and lower viscosity are expected to reach a higher degree of conversion and VPC, even if the polymerization is carried out at ambient temperature. It was verified that TEGDMA and some Bis-GMA analogues followed the trend on VPC, measured using 
STRAFI (S.G. Pereira, 2005). Overall, results were well correlated with an increase in the extent of polymerization due to the higher flexibility of the less viscous comonomer starting system and the hydrophobic character of the Bis-GMA analogues.

\begin{tabular}{|c|c|}
\hline $\begin{array}{c}\text { Monomer mixture } \\
\text { (\% by weight) }\end{array}$ & VPC $(\%)^{*}$ \\
\hline $75 \%$ Bis-GMA0 / 25\% TEGDMA & 5.9 \\
\hline $75 \%$ Bis-GMA1 / 25\% TEGDMA & 3.8 \\
\hline $75 \%$ Bis-GMA2 / 25\% TEGDMA & 7.7 \\
\hline $75 \%$ Bis-GMA3 / 25\% TEGDMA & 6.2 \\
\hline
\end{tabular}

* an error of about $0.1 \%$ should be assigned to these values.

Table 2. Volumetric polymerization shrinkage (VPC, \%) of the indicated monomer mixtures obtained after an irradiation period of $10 \mathrm{~s}$ at about $500 \mathrm{~mW} / \mathrm{cm}^{2}$.

Bis-GMA and TEGDMA, generally used to prepare resins to be used as control, were employed in order to assess the role of the filler loading in the degree of double-bond conversion, polymerization shrinkage and molecular dynamics (Nunes et al., 2008). This study showed how treated filler loading influences the photopolymerization of the dimethacrylate comonomer mixture, regarding, in particular, shrinkage and inhibition under atmospheric oxygen, present in oral environment. Bis-GMA/TEGDMA (75/25 wt.\%) resins were loaded (50 wt.\%) with hybrid filler (Ba aluminosilicate glass and pyrogenic silica, treated with $\gamma$-methacryloxy(propyl)trimethoxysilane) and light cured over a total of $30 \mathrm{~s}\left(45 \mathrm{~mW} / \mathrm{cm}^{2}\right)$. VPC, obtained using STRAFI (3.00 and $0.35 \% \pm 0.11 \%$ for the unfilled resin and for the filler loaded resin, respectively), showed a reduction on polymerization contraction and reaction inhibition at the composite resin surface with filler loading.

\subsection{Determination of leachable components from experimental dental copolymers}

The leaching of components (free molecules) from dental copolymers and composites has a potential impact on both the structural stability and the biocompatibility of the material. The latter is of much grater concern. Components may be eluted into salivary fluids and brought into contact with mucosal tissue. In addition, components may be extracted into dentine where they may diffuse toward the pulp (Ferracane, 1994).

\subsubsection{Determination of residual monomer}

The finding that a percent of the initial monomer remains unreacted while curing diacrylic dental resins, this being found as residual monomer trapped in the polymer matrix, has led some researchers to study the phenomenon of elution of these unbound molecules from the reinforced composites in different environments.

Ferracane studied the release of unreacted components from a dental resin composite (Silux, $3 \mathrm{M}$, St. Paul, MN) and from a dimethacrylate unfilled resin with identical composition of organic matrix with Silux composite (50\% Bis-GMA and 50\% DMTEG), immersed in water immediately after exposure to visible radiation, reaching to results of $1.5-2 \%$ for the two materials into a period of 7 days. Rathburn et al immersed composites in organic solvents, ethanol, chloroform and toluene, immediately after curing, and extract $4-6 \%, 7.5 \%$ and $11 \%$ respectively, from their components in a period of 7 days.

It is desirable to remain the lower amount of residual monomer after polymerization of dimethacrylate monomers. By the method proposed, the total amount of unpolymerized 
monomer trapped in the crosslinked polymer network was determined. UV spectra of the residual monomer extracted in chloroform from copolymers based on Bis-GMA2 and TEGDMA are shown in figure 4:

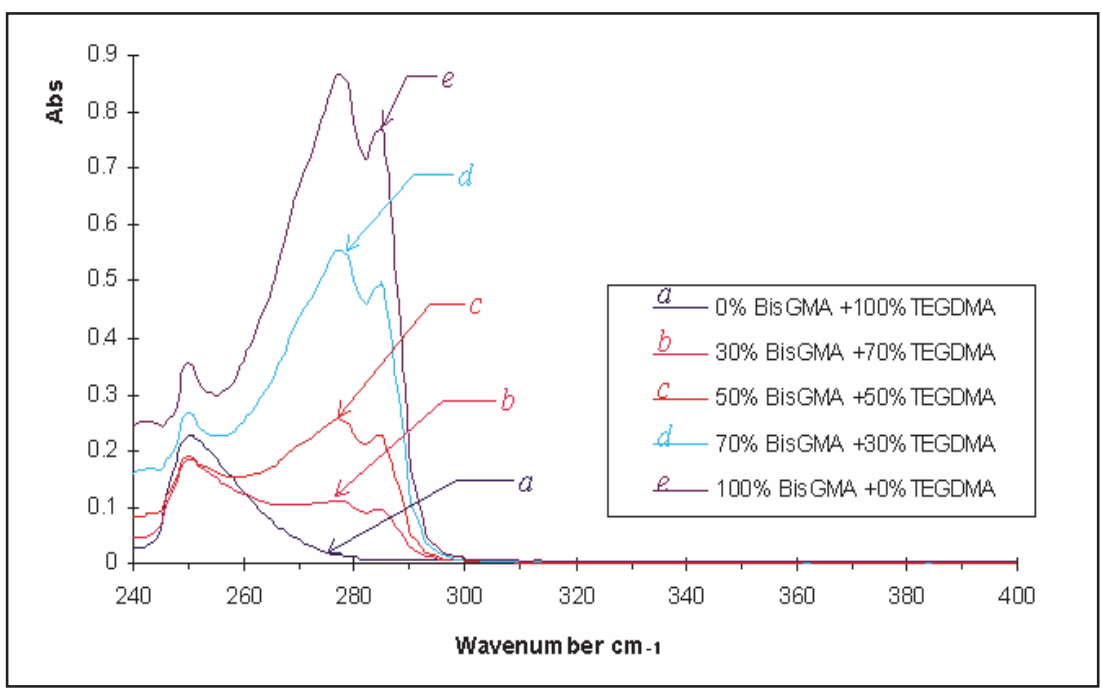

Fig. 4. UV spectra of the residual monomer extracted in chloroform from copolymers based on Bis-GMA2 and TEGDMA

Using the UV spectra of the residual monomer in chloroform and the calibrations curves of the two components, the quantities of the residual Bis-GMA2 monomer and of the TEGDMA monomer have been calculated as a percentage of the initial amount of the corresponding monomer present in the unpolymerized resin. The results are shown in table 3.

\begin{tabular}{|c|c|c|}
\hline $\begin{array}{c}\text { Bis- } \\
\text { GMA2/TEGDMA }\end{array}$ & $\begin{array}{c}\text { Extracted Bis-GMA2/Initial Bis- } \\
\text { GMA2 }\end{array}$ & $\begin{array}{c}\text { Extracted TEGDMA/Initial } \\
\text { TEGDMA }\end{array}$ \\
\hline $0 / 100$ & - & 7.3 \\
\hline $30 / 70$ & 1.1 & 7.0 \\
\hline $40 / 60$ & 1.7 & 7.0 \\
\hline $50 / 50$ & 1.5 & 6.8 \\
\hline $60 / 40$ & 1.8 & 6.85 \\
\hline $70 / 30$ & 2.3 & 6.75 \\
\hline $100 / 0$ & 2.5 & - \\
\hline
\end{tabular}

Table 3. The percent of the extracted monomers from the Bis-GMA2/TEGDMA copolymers

From the results presented in table 3 it can be seen a slight tendency of increasing the quantity of the residual Bis-GMA2 monomer and the decreasing of the quantity of the residual diluting monomer with the increasing of the Bis-GMA2/TEGDMA ratio. It can be also noticed that the residual TEGDMA percentage is about 3 up to 7 times higher than that of residual Bis-GMA2 monomer. This is due to the small and flexible molecules of TEGDMA which are more easily extracted from the polymeric matrix comparing to the rigid and large molecules of Bis-GMA2 monomer. 


\subsubsection{Determination of residual light stabilizer}

Starting from the idea that low molecular weight UV stabilizers that are not chemically bonded to the polymer network of the cured diacrylic dental resins can migrate in time from the network, being extracted into saliva, and therefore their role being compromised, in the present paragraph a way of evaluating the effectiveness of the UV stabilizers from the point of view of their permanence in the polymer matrix is presented. In order to evaluate the UV stabilizers permanence, the quantity (percent) of extractable stabilizer from the polymer matrix was determined.

The investigated UV stabilizers were conventional and unconventional UV stabilizers (polymer-bound stabilizers) belonging to the hydroxybenzophenones, hydroxyphenylbenzotriazoles and sterically hindered amines (HALS) classes (Table 4). In order to calculate the amount of extracted UV stabilizers, there were determined the extinction coefficients of the stabilizers at every characteristic wavelength. The ultraviolet extinction coefficients of investigated stabilizers are shown in table 5. After the extraction of stabilized copolymer powders in chloroform, the UV spectra of the chloroformic extracts were recorded.

\begin{tabular}{|l|l|}
\hline $\begin{array}{l}\text { Chemical structure of the light- } \\
\text { stabilizers }\end{array}$ & $\begin{array}{l}\text { Trade namel } \\
\text { Chemical name }\end{array}$ \\
\hline & $\begin{array}{l}\text { Chimassorb 81 } \\
\text { 2-hydroxy-4-fi- } \\
\text { actyloxybenzo- } \\
\text { ihenone }\end{array}$ \\
\hline
\end{tabular}

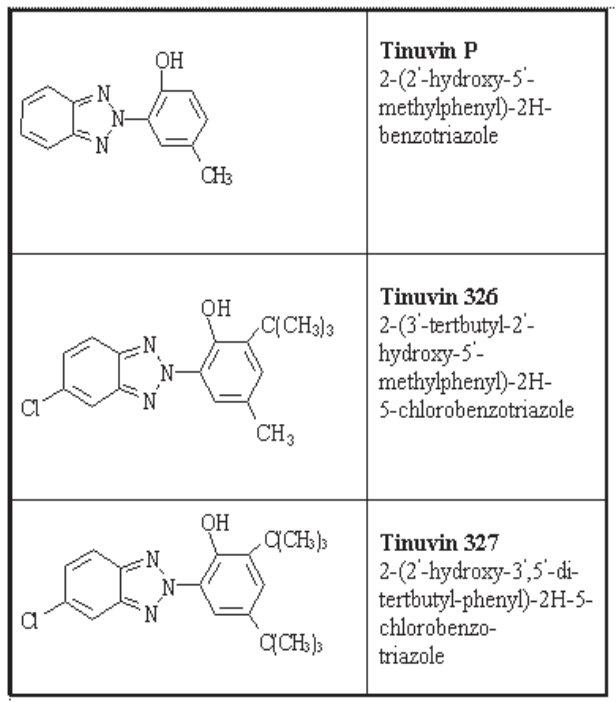

Table 4. The investigated light-stabilizers, conventional (Chimassorb 81, Tinuvin P, 326, 327) and polymerizable ones (Cyasorb UV 2098 and VP Sanduvor PR-31)

The spectra of chloroformic extracts corresponding to TEGDMA polymers and Bis-GMA2 polymers stabilized with Cyasorb UV 2098, VP Sanduvor PR 31 and Chimassorb 81, obtained by photochemical polymerization and chemical polymerization are presented in figure 5, 6, 7, 8. In order to determinate the UV stabilizer amount extracted from the polymer matrix it was used a characteristical wavelength of the stabilizer over $300 \mathrm{~nm}$, where the residual monomer and other additives don't absorb.

The percent of extracted stabilizers resulted from the chemically and photo-chemically initiated polymers obtained by the polymerization of TEGDMA and Bis-GMA2 and by copolymerization of Bis-GMA2/TEGDMA are presented in tables 6 and 7 . 


\begin{tabular}{|c|c|c|c|c|c|c|c|}
\hline No. & UV Stabilizer & $\lambda_{1}$ & $\lambda_{2}$ & $\lambda_{3}$ & $\varepsilon_{1}$ & $\varepsilon_{2}$ & $\varepsilon_{3}$ \\
\hline A. & Chimassorb 81 & $242 \mathrm{~nm}$ & $286 \mathrm{~nm}$ & $325 \mathrm{~nm}$ & 16233 & 24466 & 16266 \\
\hline B. & CyasorbUV 2098 & $244 \mathrm{~nm}$ & $285 \mathrm{~nm}$ & $325 \mathrm{~nm}$ & 9660 & 15233 & 9600 \\
\hline C. & VP Sanduvor PR 31 & $312 \mathrm{~nm}$ & & & 29960 & & \\
\hline D & Tinuvin P & $250 \mathrm{~nm}$ & $301 \mathrm{~nm}$ & $341 \mathrm{~nm}$ & 8026 & 16984 & 20123 \\
\hline E & Tinuvin 326 & $253 \mathrm{~nm}$ & $313 \mathrm{~nm}$ & $354 \mathrm{~nm}$ & 11020 & 27880 & 31040 \\
\hline F & Tinuvin 327 & $254 \mathrm{~nm}$ & $315 \mathrm{~nm}$ & $354 \mathrm{~nm}$ & 2599 & 11013 & 12334 \\
\hline
\end{tabular}

Table 5. Ultraviolet extiction coefficients of investigated UV stabilizers

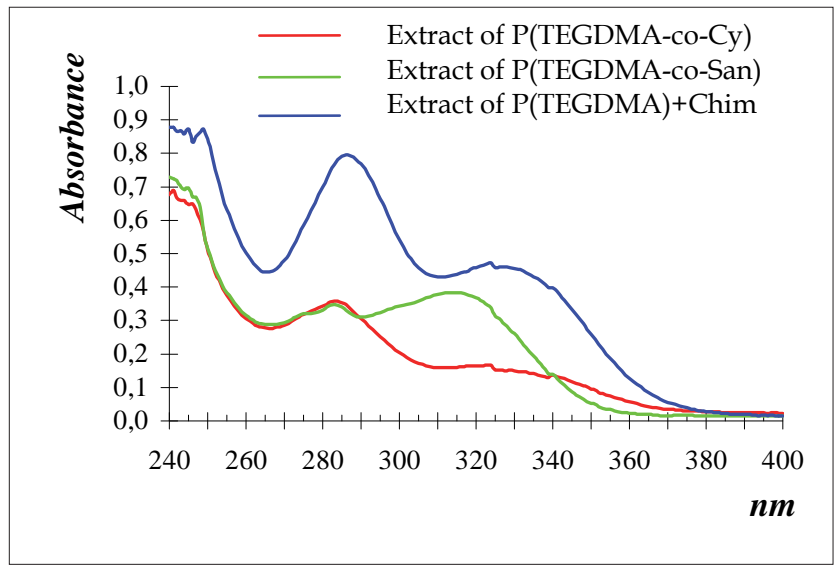

Fig. 5. The spectra of chloroformic extracts corresponding to TEGDMA polymers stabilized with Cyasorb UV 2098, VP Sanduvor PR 31 and Chimassorb 81, obtained by photochemical polymerization

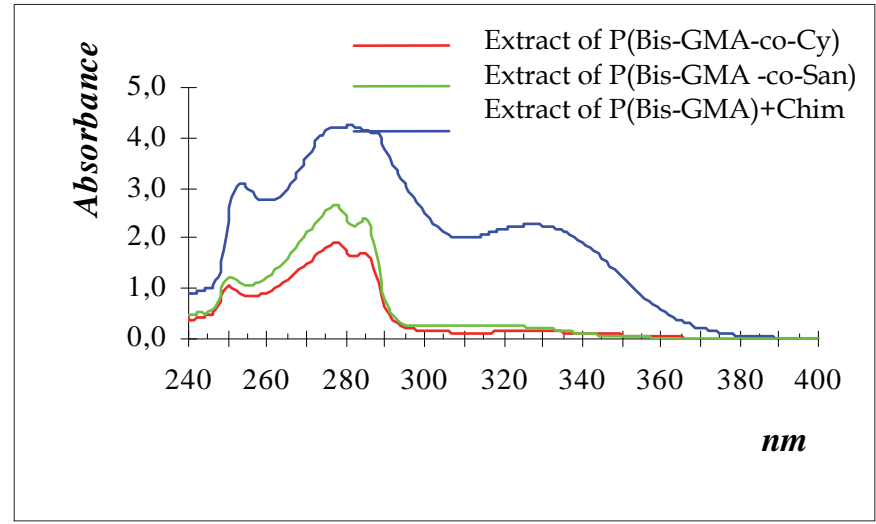

Fig. 6. The spectra of chloroformic extracts correponding to Bis-GMA2 polymers stabilized with Cyasorb UV 2098, VP Sanduvor PR 31 and Chimassorb 81, obtained by photochemical polymerization 


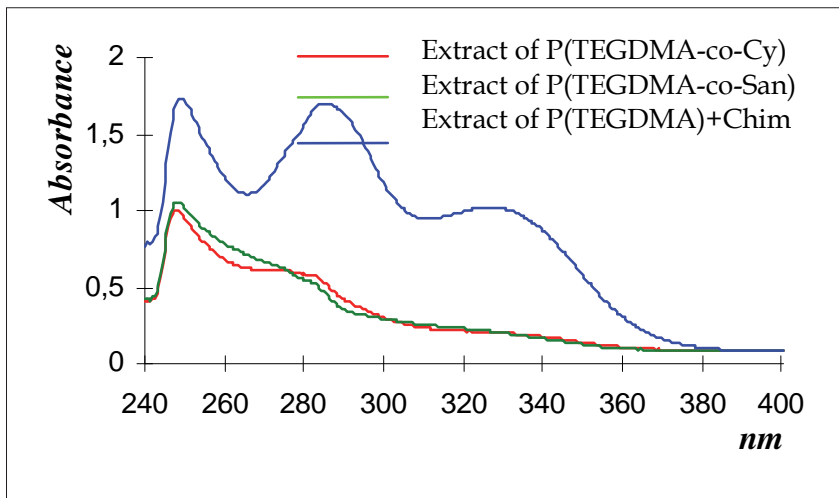

Fig. 7. The spectra of chloroformic extracts corresponding to TEGDMA polymers stabilized with Cyasorb UV 2098, VP Sanduvor PR 31 and Chimassorb 81, obtained by chemical polymerization

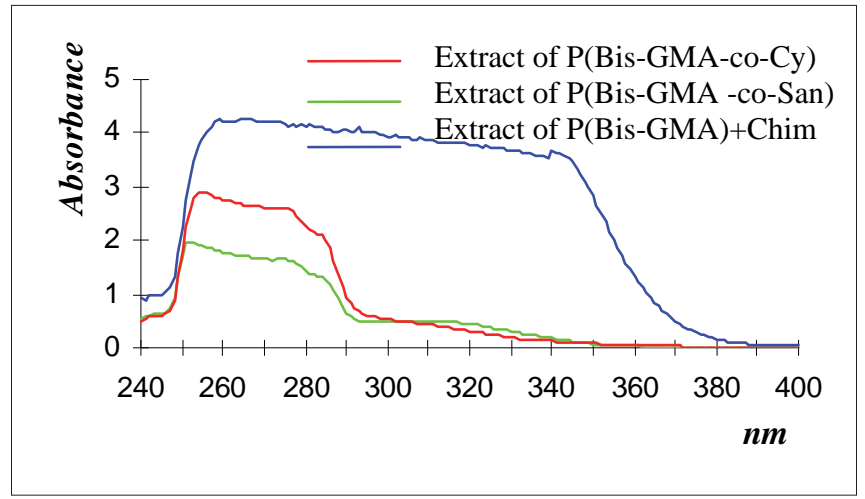

Fig. 8. The spectra of chloroformic extracts corresponding to Bis-GMA 2 polymers stabilized with Cyasorb UV 2098, VP Sanduvor PR 31 and Chimassorb 81, obtained by chemical polymerization

\begin{tabular}{|c|c|c|c|}
\hline $\begin{array}{c}\text { Chemically initiated } \\
\text { polymerization }\end{array}$ & P(TEGDMA) & P(Bis-GMA2) & $\begin{array}{c}\text { P(Bis-GMA2-co- } \\
\text { TEGDMA) }\end{array}$ \\
\hline Cyasorb UV 2098 & $6.5 \%$ & $6.5 \%$ & $7.15 \%$ \\
\hline VP Sanduvor PR-31 & $3.56 \%$ & $6.16 \%$ & $5.85 \%$ \\
\hline Chimassorb 81 & $20.22 \%$ & $59.03 \%$ & $48.75 \%$ \\
\hline Tinuvin P & $28.25 \%$ & $40.3 \%$ & $38.22 \%$ \\
\hline Tinuvin 327 & $27.0 \%$ & $35.7 \%$ & $34.8 \%$ \\
\hline Tinuvin 326 & $27.55 \%$ & $39.8 \%$ & $38.8 \%$ \\
\hline
\end{tabular}

Table 6 . The percent of extracted stabilizer $\mathrm{p} \%$ resulted from the chemically initiated polymers 


\begin{tabular}{|c|c|c|c|}
\hline $\begin{array}{c}\text { Photohemically initiated } \\
\text { polymerization }\end{array}$ & P(TEGDMA) & P(Bis-GMA2) & $\begin{array}{c}\text { P(Bis-GMA2-co- } \\
\text { TEGDMA) }\end{array}$ \\
\hline Cyasorb UV 2098 & $5.43 \%$ & $4.86 \%$ & $5.01 \%$ \\
\hline VP Sanduvor PR-31 & $3.65 \%$ & $4.46 \%$ & $3.65 \%$ \\
\hline Chimassorb 81 & $30.2 \%$ & $44.00 \%$ & $37.88 \%$ \\
\hline Tinuvin P & $22.4 \%$ & $38.44 \%$ & $28.77 \%$ \\
\hline Tinuvin 327 & $24.0 \%$ & $39.02 \%$ & $33.12 \%$ \\
\hline Tinuvin 326 & $25.4 \%$ & $38.5 \%$ & $31.5 \%$ \\
\hline
\end{tabular}

Table 7. The percent of extracted stabilizer $\mathrm{p} \%$ resulted from the photo-chemically initiated polymers

The results of the extraction tests have underlined the net superiority of the polymerizable stabilizers Cyasorb UV 2098 and VP Sanduvor PR-31 compared to the conventional stabilizers, the percent of polymerizable stabilizer extracted from the polymer matrix being 4 to 10 times smaller than the one of the conventional stabilizer.

\subsubsection{Determination of mechanical properties}

High conversion is not a goal in itself, however. If the monomer is very flexible and not sufficiently bulky, the degree of conversion will be high, but the mechanical properties will be poor. High mechanical properties are particularly important in the process of mastication, where the greatest loads are experienced by the tooth structures. Compressive strength (CS), diametral tensile strength (DTS) and flexural strength (FS) are important parameters for the comparison of dental restorative composites.

The composition of the resins of the experimental composites used for mechanical tests is presented in table 8:

\begin{tabular}{|c|c|c|c|c|c|}
\hline No. & $\begin{array}{c}\text { Bis-GMA0 } \\
\%\end{array}$ & $\begin{array}{c}\text { Bis-GMA 1 } \\
\%\end{array}$ & $\begin{array}{c}\text { Bis-GMA 2 } \\
\%\end{array}$ & Bis-GMA 3 & $\begin{array}{c}\text { TEGDMA } \\
\%\end{array}$ \\
\hline R1. & 65 & & & & 35 \\
\hline R2. & & 65 & & & 35 \\
\hline R3. & & & 65 & & 35 \\
\hline R4. & & & & 65 & 35 \\
\hline
\end{tabular}

Table 8. Composition of the resins in the experimental composites

Compressive strengths, diametral tensile strengths and flexural strengths of the new experimental dental composites as function of composition is shown in figure 9 . The results presented in figure 9 show that the mechanical properties are influenced by the type of BisGMA monomer presented in resin composite.

The compressive strengths obtained for experimental composites were relatively high, and range between 240 and $279 \mathrm{MPa}$. Bis-GMA2-based composite present the highest values for CS, followed by Bis-GMA0-based composite and Bis-GMA1-based composite. Bis-GMA3 composite showed the lowest value for CS.

The diametral tensile strengths are about in the same ranges for all four composites (37.2 $\mathrm{MPa}$ for Bis-GMA3-based composite, 42.0 MPa in the case of Bis-GMA2-based composite and 45.0 MPa for Bis-GMA0-based composite and 45.3 MPa for Bis-GMA1 composite). 


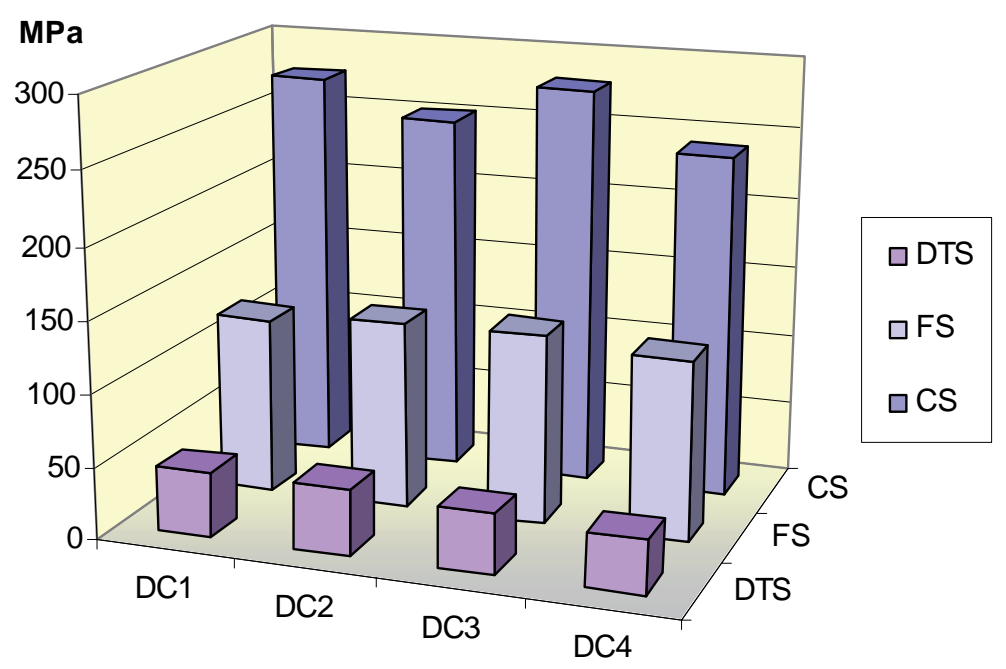

Fig. 9. The strength properties of experimental resin composites

The flexural strengths are high, being over $120 \mathrm{MPa}$ for all experimental composites. The highest values were obtained for Bis-GMA2-containing composite (132.0 MPa), followed by Bis-GMA1-based composite (130.8 MPa). Among the synthesized Bis-GMA type oligomers, Bis-GMA2 leads to the obtaining of composites with highest CS and FS. The highest value for DTS was obtained in the case of Bis-GMA1-based composite (45.3 MPa).

Recently, relevant mechanical properties of Bis-GMA/TEGDMA and some Bis-GMA analogues/TEGDMA composite resins were evaluated as a function of filler loading and polymeric matrix composition (Pereira SG, 2007).

\subsubsection{Determination of flexural strengths of fiber reinforced composites (FRCs)}

The metal alloys used to make substructures that reinforced crowns and fixed prostheses are strong and rigid, but they are not esthetic and present corrosion phenomena, leading to an allergic reaction of some patients. FRCs materials could be used in any situation in which the main purpose is esthetics, because they present excellent esthetic properties. The mechanical properties increase very much because of the reinforcing fibers, getting ahead of the values obtained for the metal alloys, which are used today in dentistry (Freilich et al., 2000).

In the present work, a series of fiber reinforced composites (FRCs) using Bis-GMA2-based resin matrix and continuous unidirectional bundles, respectively woven E-glass fibers was obtained (table 9). The resins contained 65\% Bis-GMA2 and 35\% TEGDMA. The continuous unidirectional bundle contained about 800 E-glass fibers with $15 \pm 1 \mu \mathrm{m}$ diameter. Woven glass fibers contained about 200 fibers having $2 \mathrm{~mm}$ width and $9 \pm 1 \mu \mathrm{m}$ diameter. The fibers were silanated with A-1100 and A-174 silanes, and silanated and treated with PMMA, respectively. After initial photopolymerization, the specimens were postcured by barrothermal treatment at $135^{\circ} \mathrm{C}$ temperature and 60 psi pressure, for 20 minutes, using a 'belleGlass" oven. The flexural strengths for the light cured and post-cured experimental FRCs were determined (fig. 10 and fig. 11) 


\begin{tabular}{|c|c|c|c|c|}
\hline \multirow{2}{*}{ Code } & \multirow{2}{*}{ Resin } & \multicolumn{2}{|l|}{ E-glass fibers } & \multirow{2}{*}{$\begin{array}{c}\text { Reinfor } \\
- \\
\text { cement } \\
\% \text { wt }\end{array}$} \\
\hline & & Type & Treatment & \\
\hline Control & $\begin{array}{c}\text { 65\% Bis-GMA2+ } \\
\text { 35\% TEGDMA }\end{array}$ & - & - & - \\
\hline 10FIRC-S & $\begin{array}{c}\text { 65\% Bis-GMA2+ } \\
\text { 35\% TEGDMA } \\
\end{array}$ & $\begin{array}{l}10 \text { continuous unidirectional } \\
\text { bundles }\end{array}$ & Silane & 43.50 \\
\hline 20FIRC-S & $\begin{array}{c}\text { 65\% Bis-GMA2+ } \\
\text { 35\% TEGDMA } \\
\end{array}$ & $\begin{array}{l}20 \text { continuous unidirectional } \\
\text { bundles }\end{array}$ & Silane & 71.62 \\
\hline $\begin{array}{c}\text { 10FlRC- } \\
\text { SP }\end{array}$ & $\begin{array}{c}\text { 65\% Bis-GMA2+ } \\
\text { 35\% TEGDMA }\end{array}$ & $\begin{array}{c}10 \text { continuous unidirectional } \\
\text { bundles }\end{array}$ & $\begin{array}{l}\text { Silane+ } \\
\text { PMMA }\end{array}$ & 55.77 \\
\hline $\begin{array}{l}\text { 15FlRC- } \\
\text { SP }\end{array}$ & $\begin{array}{c}\text { 65\% Bis-GMA2+ } \\
\text { 35\% TEGDMA }\end{array}$ & $\begin{array}{l}15 \text { continuous unidirectional } \\
\text { bundles }\end{array}$ & $\begin{array}{l}\text { Silane } \\
+ \text { PMMA }\end{array}$ & 78.98 \\
\hline 2FwRC-S & $\begin{array}{c}\text { 65\% Bis-GMA2+ } \\
\text { 35\% TEGDMA }\end{array}$ & 2 woven E-glass fibers & Silane & 29.67 \\
\hline $\begin{array}{l}\text { 2FwRC- } \\
\text { SP }\end{array}$ & $\begin{array}{c}65 \% \text { Bis-GMA2+ } \\
\text { 35\% TEGDMA }\end{array}$ & 2 woven E-glass fibers & $\begin{array}{l}\text { Silane } \\
+ \text { PMMA }\end{array}$ & 42.54 \\
\hline $\begin{array}{l}\text { 3FwRC- } \\
\text { SP }\end{array}$ & $\begin{array}{c}\text { 65\% Bis-GMA2+ } \\
\text { 35\% TEGDMA } \\
\end{array}$ & 3 woven E-glass fibers & $\begin{array}{c}\text { Silane+PMM } \\
\text { A } \\
\end{array}$ & 47.28 \\
\hline
\end{tabular}

Table 9. Composition of the experimental fiber-reinforced composites

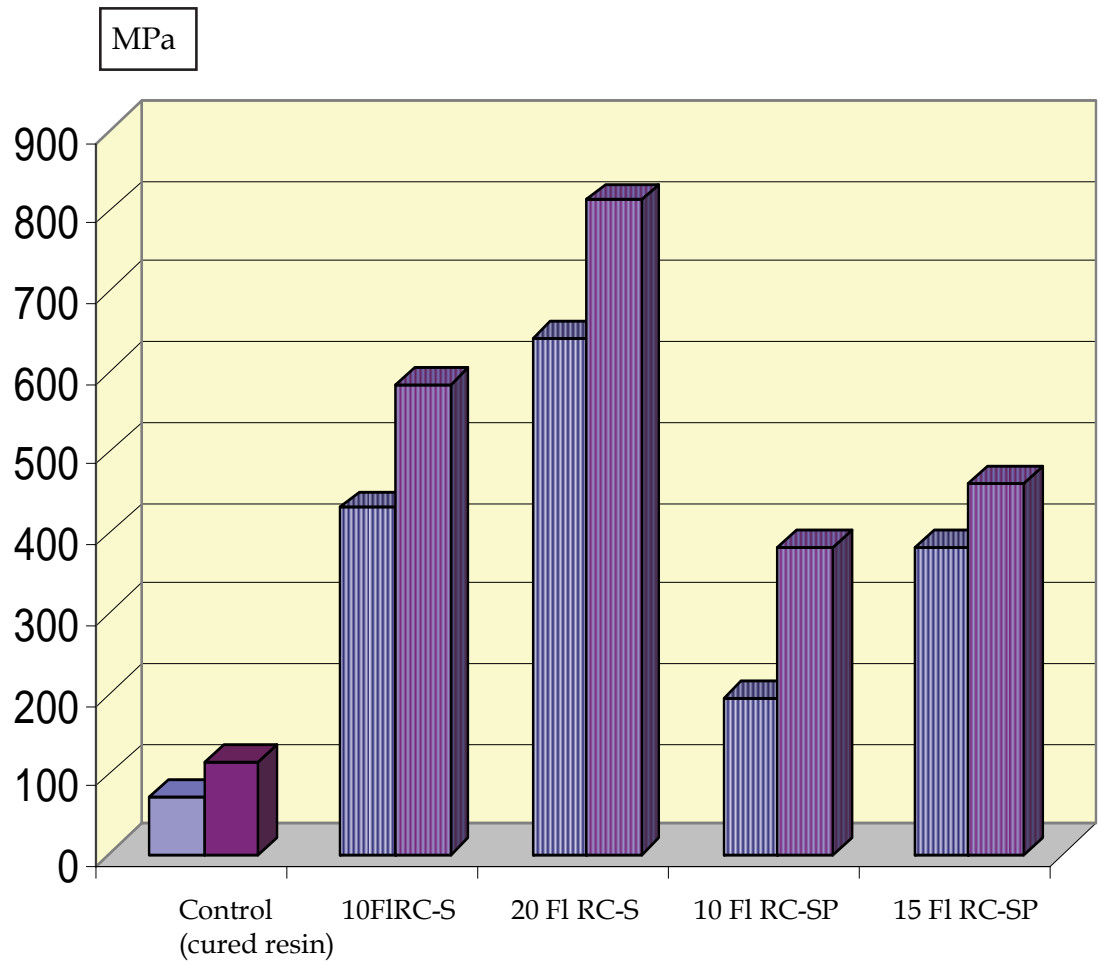

Fig. 10. Flexural strength for the light-cured $\amalg$ and post- cured $\amalg$ FRCs containing unidirectional glass fibers 


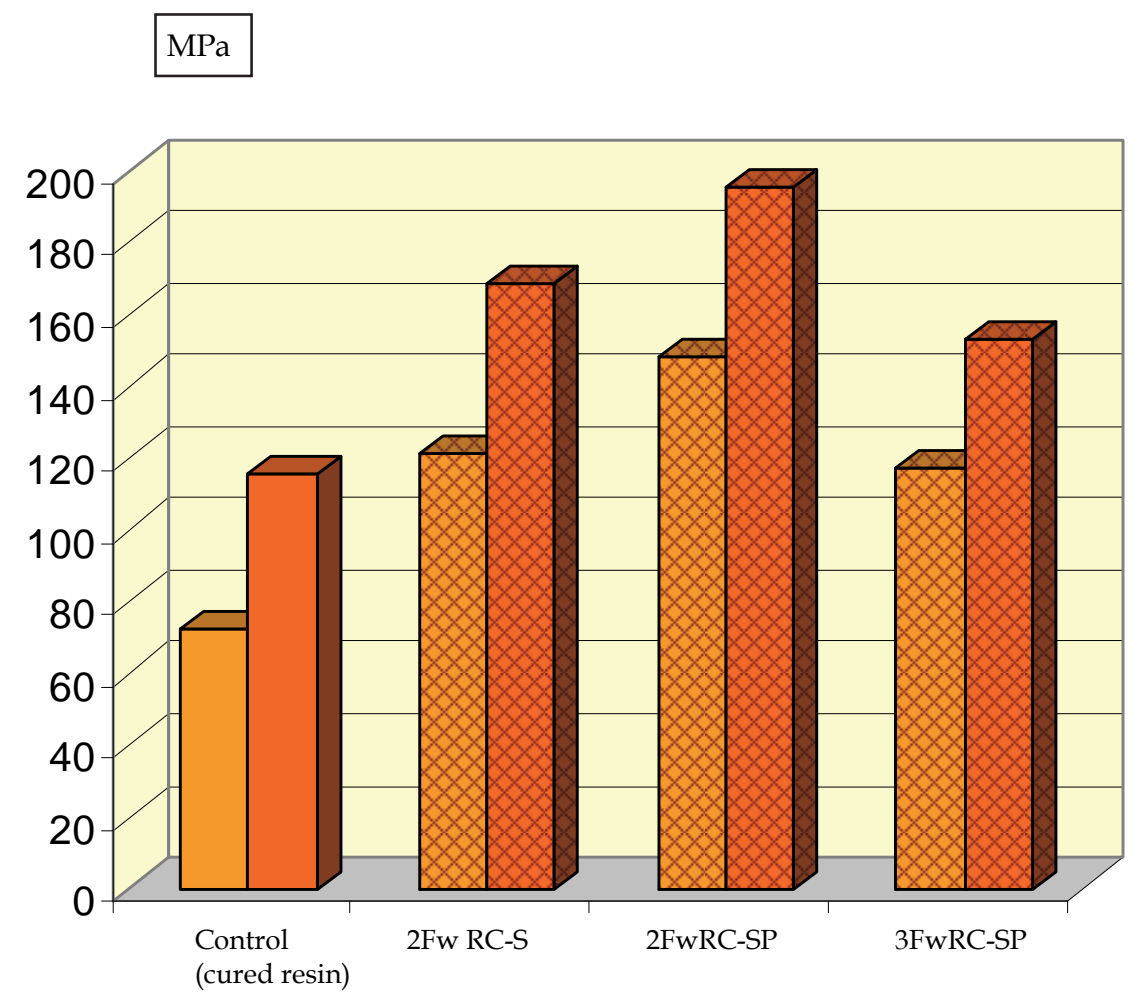

Fig. 11. Flexural strength for the light-cured $\$$ and post- cured $\square$ FCs containing woven glass fibers

The amount and the type of fibers have a major influence upon the flexural strength values. The FRCs based on linear bundles of fibers recorded higher values for flexural strength than the FRCs based on woven E-glass fibers at the same reinforcement. All the post-cured FRCs presented higher flexural strength values comparing with the corresponding light-cured FRCs. The highest values for flexural strength were obtained in the case of post-cured FRC containing 20 silanated continuous unidirectional bundles of E-glass fibers (812 MPa).

The fracture appearances of the experimental FRCs as the consequence of the flexural stresses have been investigated by SEM. As one can see from the figure below, in the case of FRCs with woven fibers, the resin can not penetrate well enough between the fibers in order to ensure a strong connection of the fibers with the polymer matrix in the cured composites. This behavior was observed in the SEM images of fracture composites when the phenomenon of delamination of fibers from the polymeric matrix after the mechanical stress appeared. Within the limits of our experimental test, fibers with PMMA prepolymer coating were beneficial only for manipulative reasons. Mechanical studies and microscopic images revealed that the best mechanical properties were obtained in the case of silanized glass fibers without a PMMA preimpregnation 


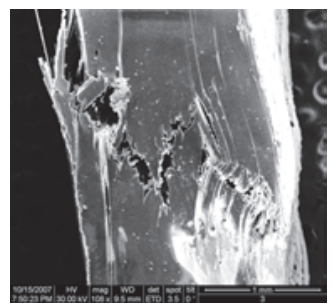

a

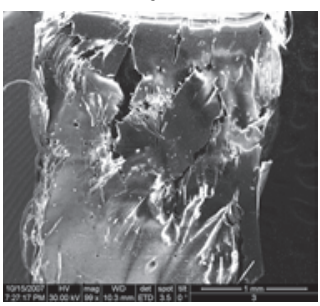

$\mathrm{e}$

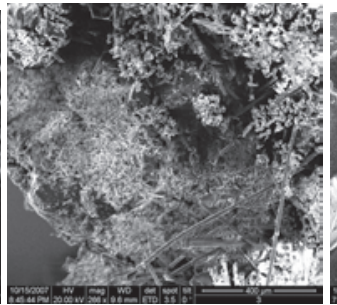

$\mathrm{b}$

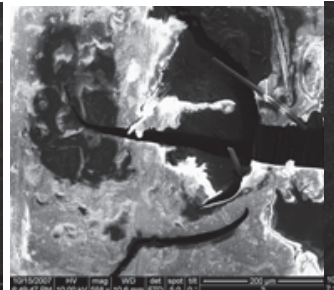

$\mathrm{f}$

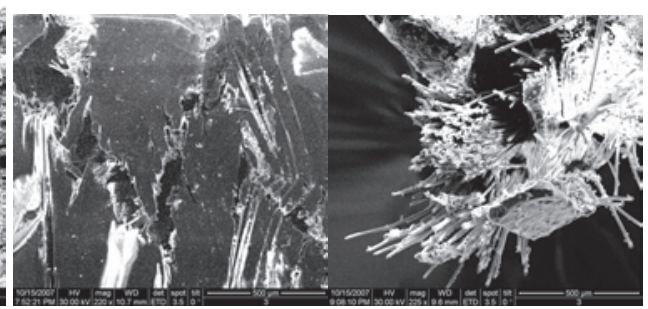

C

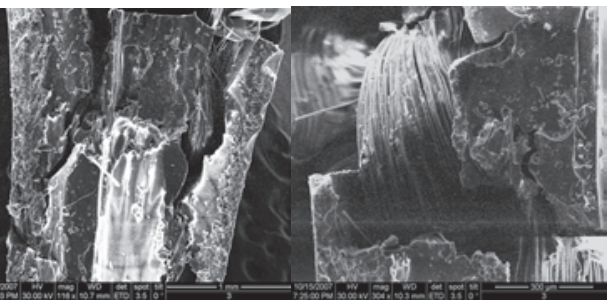

$\mathrm{g}$

$\mathrm{h}$

Fig. 12. SEM photomicrographs. Fracture appearance of 3 FwRC-SP $(a, b), 15 F I R C-S P(c, d)$, 2FwRC-S (e, f), 3FwRC-SP(g, h)

\subsubsection{Determination of color changes}

$\Delta \mathbf{a}^{*}, \Delta \mathbf{b}^{*} \Delta \mathbf{L}^{*}$ coordinates and $\Delta \mathbf{E}^{*}$ color changes of the stabilized samples of light-cured composites after exposure 1, 7 and 30 days to UV light are presented in figure 13a, b, c, d.
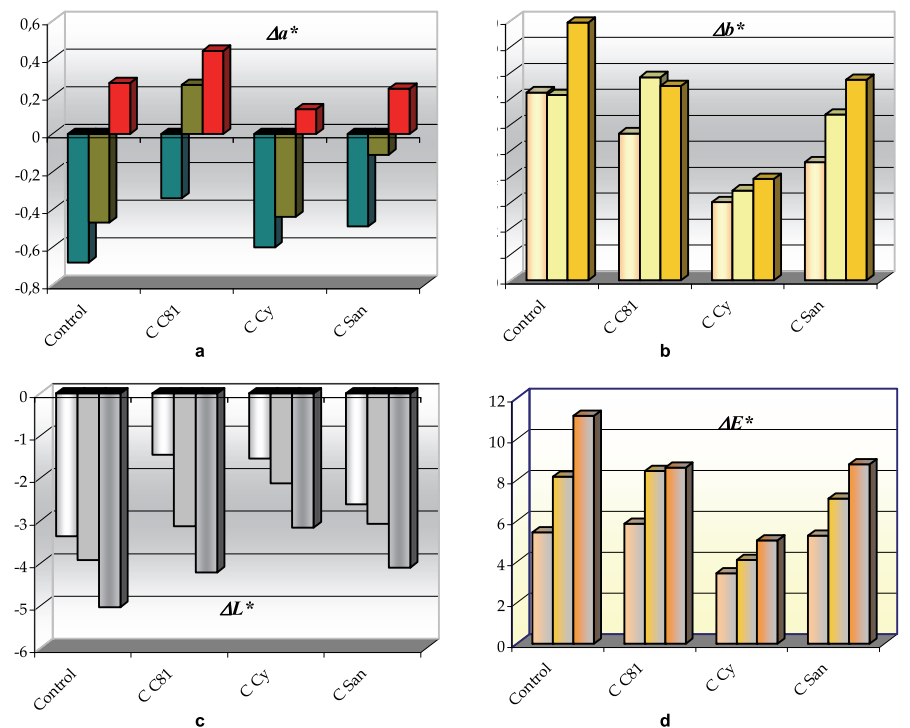

Fig. 13. $\Delta \mathbf{a}^{*}(\mathrm{a}), \Delta \mathbf{b}^{*}(\mathrm{~b}), \Delta \mathbf{L}^{*}$ (c) coordinates and $\Delta \mathbf{E}^{*}(\mathrm{~d})$ color changes of the stabilized samples of light-cured composites after exposure 1day (the first bar), 7 days (the second bar) and 30 days (the third bar) to UV light 
The light curing resins were prepared using 65\% Bis-GMA2 monomer and 35\% TEGDMA. The resins have been stabilized using conventional and polymerizable stabilizers (Chimassorb 81, CyasorbUV 2098 and VP Sanduvor PR 31). As a control was used the resin composite that don't contain a stabilizer in the composition.

An increasing in b coordinate (yellowing) and a decreasing in L coordinate (darkening) of the experimental composite samples after the UV illumination was recorded. The color changes were more intense for the samples that don't contain a stabilizer than for the stabilized composites. Quantitatively, the color changes ranged from 2.3 to 11.6 CIELAB units. The samples stabilized with Chimassorb 81 and VP Sanduvor PR 31 presents relatively the same color change after 30 days of illumination.

The effectiveness of Cyasorb UV 2098 in time can be explained by the high compatibility of this stabilizer with the monomer mixture and by its capacity of polymerization with the monomers.

\subsubsection{Determination of water sorption}

The resin matrix used in dental materials absorbs saliva from the environment. Saliva is mostly water (more than $99 \%$ ) and less than 1\% solids (macromolecules like proteins, sugars, calcium, sodium and chloride, amino acids, free glucose etc). Water can penetrate in the gaps of the polymer network, reaching around functional groups which are able to deliver hydrogen bonds. Sorption of saliva may produce physical and chemical processes and can lead to a change of structure and properties of polymer network. The sorption of saliva is accompanied by dimensional changes, deleterious effects on the structure and function of dental polymers and composites. This behavior affects the restoration life, therefore water sorption of these materials should be as low as possible.

Water sorption values for the experimental resin composites with the composition presented in the 3.3.3. Paragraph, after 7 days water storage are presented in table 9:

From the table 9 one can be noticed that the sorption values obtained for all resin composites are in the limits of ISO 4049 International standard. The lowest value was obtained for the Bis-GMA2-based composite. This behavior could be due to the lower quantity of hydroxyl groups from the Bis-GMA2 superior oligomers contained in the same amount of monomer mixture comparing to Bis-GMA0. Bis-GMA1-based composite and Bis-GMA3-based composite proved to absorb more water than Bis-GMA0 and Bis-GMA2.

\begin{tabular}{|l|l|}
\hline Resin Composite & Water sorption $\mu \mathrm{g} / \mathrm{mm}^{3}$ \\
\hline DC1 & 9.45 \\
\hline DC2 & 11.88 \\
\hline DC3 & 7.36 \\
\hline DC4 & 19.25 \\
\hline
\end{tabular}

Table 9. Water sorption of the experimental resin composites

\subsubsection{Investigation of the adhesion of the resin composites to dental tissues}

The polymerization shrinkage produces contraction stresses generally concentrated at the adhesive interface (Davidson \& Feilzer, 1997; Davidson et al., 1984) leading to generating 
cuspal deflection (Causton et al., 1985; Cara et al., 2010) and cracks in the surrounding dentin and enamel (Jorgensen et al., 1975). Polymerization shrinkage stress may compromise the dental tissue/material interface leading to bacterial microleakage (KempScholte \& Davidson, 1990) and ultimately to marginal discoloration, marginal debondings, secondary caries, pulpal inflammation, or necrosis (Letzel, 1989).

The basic mechanism of bonding the resin composites (RCs) to enamel and dentin is essentially an exchange process involving replacement of minerals removed from the hard dental tissue by resin monomers, which upon setting become micro-mechanically interlocked in the acid-induced porosities. Beside the micro-mechanical adhesion, the physical and chemical interactions with the tooth structure are also important. Because the RC pastes are very viscous, they are not able to adhere to the enamel and dentin surfaces, so it is necessary to use an adhesive system of low viscosity before applying the RCs.

Generally, an adhesive system involves three steps:

1. Conditioning step in which the smear layer is removed, the dentin and enamel are demineralized and the dentin tubules are opened;

2. Priming step in which the hydrophylic surface layer is transformed into a hydrophobic surface layer. The primer can be represented by M-R-X molecules, where M-methacrylic group, X-functional group that can create a chemical bond to the dentin surface, $\mathrm{R}$ spacer. Theoretically, the primer should be applied in a monomolecular layer, should be chemically bond to dental tissues before the bonding is applied and should cover the surfaces with polymerizable groups.

3. Application and curing the low viscosity adhesive resin (bonding);

The present paragraph presents the adhesion of the experimental resin composites to dental tissues by investigating the tooth / RCs interfaces using the scanning electron microscopy method.

For the adhesion test, there were prepared three experimental adhesive systems containing the same etchant and the same primer but different bondings. The primer was based on the acrylic acid/itaconic acid copolymer grafted with methacrylic groups. The bondings were prepared for each composite material. Each bonding contain the base monomer that was present in the corresponding composite, Bis-GMA0, Bis-GMA1 or Bis-GMA2 respectively. As control was used the three step adhesive OptiBond FL from Sybron-Kerr Orange, CA, USA.

The main differences between the experimental adhesives and the control adhesive were the composition and the curing procedure of the primers and bondings. The bonding of OptiBond FL is a filled resin, unlike the experimental bondings that are unfilled resins. In the case of control adhesive, the primer was only dried and the bonding was light cured for $30 \mathrm{~s}$. In the case of the experimental adhesives, the primer was light cured for $30 \mathrm{~s}$ in order to obtain an elastic layer fixed on the tooth surfaces that can reduce the stress at the interface, and the bondings were light cured for 60 seconds.

The composites were prepared using 75\% Bis-GMA-type monomer and 25\% TEGDMA mixture. Herculite resin composite was used as a control.

The composition and the procedure of applying the three steps adhesive systems were presented in table 11.

SEM photomicrographs of dentin surface treated with three step Bis-GMA1 based adhesive system and Bis-GMA1 based composite are presented in fig. 14 (1a-1c thick layer and 1d-1f thin layer). 


\begin{tabular}{|c|c|c|}
\hline $\begin{array}{l}\text { Material } \\
\text { /Manufacturer }\end{array}$ & Composition & Procedure \\
\hline $\begin{array}{l}\text { Control adhesive } \\
\text { system } \\
\text { OptiBond FL } \\
\text { Sybron-Kerr } \\
\text { Orange, CA, USA }\end{array}$ & $\begin{array}{l}\text { Etchant-37\% phosphoric acid } \\
\text { Primer:2-hydroxyethylmethacrylate (HEMA) } \\
\text { Glycerophosphate-dimethacrylate (GPDM), } \\
\text { Phtalic acid monomethacrylate (MMEP), ethanol, } \\
\text { water, initiators } \\
\text { Bonding : Bis-phenol A diglycidylmethacrylate } \\
\text { (Bis-GMA) } \\
\text { 2-hydroxyethylmethacrylate (HEMA) } \\
\text { Glycerol-dimethacrylate (GDMA), initiators } \\
\text { Barium-aluminium borosilicate glass, , Disodium } \\
\text { hexa-fluoro-silicate Fumed silica }\end{array}$ & $\begin{array}{l}\text { Etchant: apply } \\
\text { 15s. rinse } 15 \mathrm{~s} \text {. and } \\
\text { dry } \\
\text { Primer: apply one } \\
\text { coat, } \\
\text { dry } 5 \mathrm{~s} . \\
\text { Bonding: apply } \\
\text { one coat, light } \\
\text { cure for } 30 \mathrm{~s}\end{array}$ \\
\hline $\begin{array}{l}3 \text { Experimental } \\
\text { adhesive systems }\end{array}$ & $\begin{array}{l}\text { Etchant-37\% phosphoric acid } \\
\text { Primer: Copolymer of acrylic acid/itaconic acid } \\
\text { grafted with methacryloiloxiethylcarbamoyl- } \\
\text { aminoethanol } \\
\text { HEMA, water, ethanol, initiators } \\
\text { Bondings: Bis-GMA0/Bis-GMA1/ Bis-GMA2, } \\
\text { TEGDMA, HEMA initiators }\end{array}$ & $\begin{array}{l}\text { Etchant: apply } \\
15 \text { s. } \\
\text { Rinse } 15 \text { s. and } \\
\text { dry } \\
\text { Primer: apply one } \\
\text { coat } \\
15 \text { sec., dry } 5 \text { s. , } \\
\text { cure } 30 \mathrm{~s} \\
\text { Bonding: apply } \\
\text { one } \\
\text { coat, light cure } \\
\text { for } 60 \mathrm{~s}\end{array}$ \\
\hline
\end{tabular}

Table 11. The composition and the procedure of applying the three steps adhesive systems SEM photomicrographs of dentin surface treated with three step Bis-GMA2-based adhesive system and Bis-GMA2- based composite are presented in fig. 15. SEM photomicrographs of dentin surface treated with three step Bis-GMA0-based adhesive system and Bis-GMA0based composite are presented in fig. 16. SEM photomicrographs of dentin surface treated with Optibond FL adhesive system and Herculite composite are presented in fig. 17.

From figure 14 one can observe that the adhesive layer follows the shape of dentin surface having about the same width. Signs of strong interactions between the resin and dentin can be observed. From figure 15 it can be seen that the adhesive layers don't have the same width along the dentin surface. Some dislocations appeared. Figure 16 shows that the adhesive layer is not uniform. No interactions can be seen. From figure 17 one can observe that the adhesive layer is relatively uniform and the filler particles presented in the bonding can be seen. 


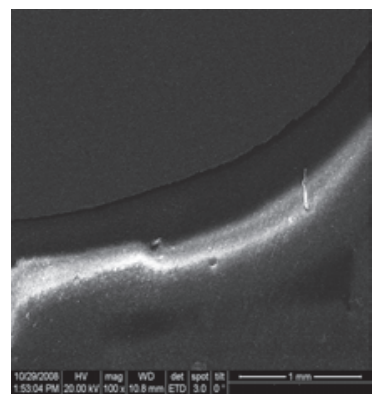

1a

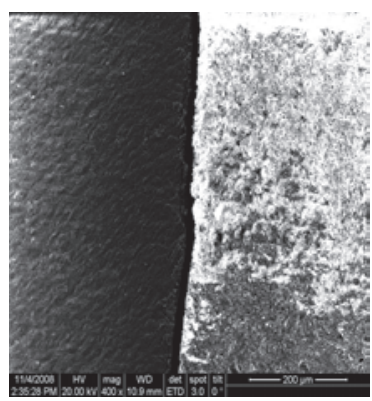

$2 \mathrm{a}$

$x 100$

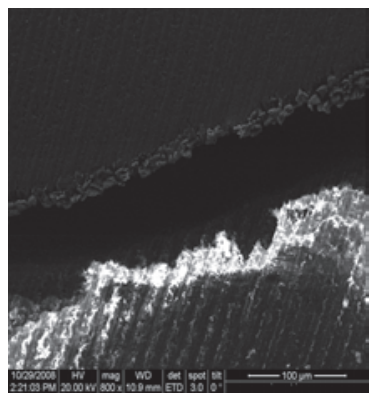

$1 b$

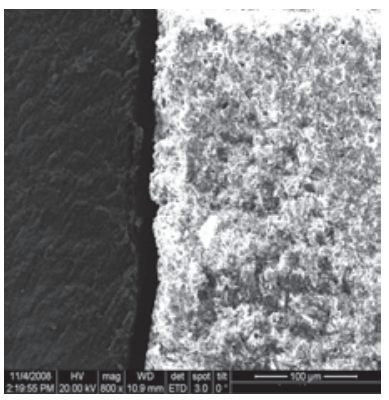

$2 b$

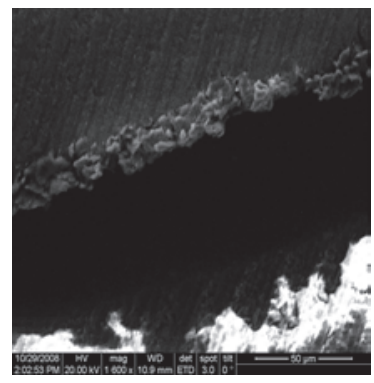

1c

$x 1600$

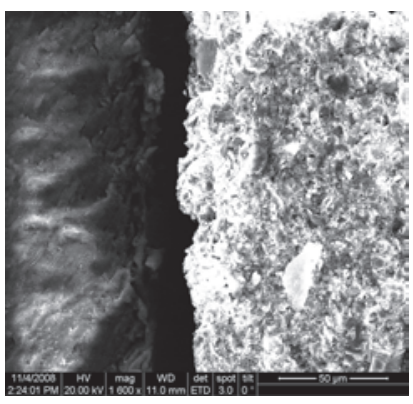

2c

$x 1600$

Fig. 14. SEM photomicrographs of dentin surface treated with three step Bis-GMA1 based adhesive system (1a-1c thick layer and 1d-1f thin layer) and Bis-GMA1 based composite

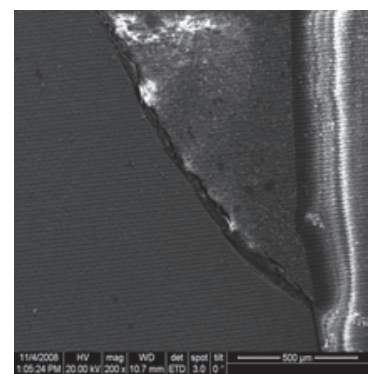

$2 \mathrm{a} \quad \times 200$

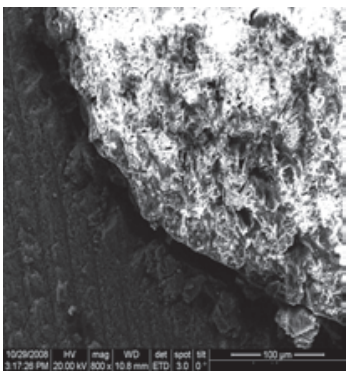

$2 b$

$x 800$

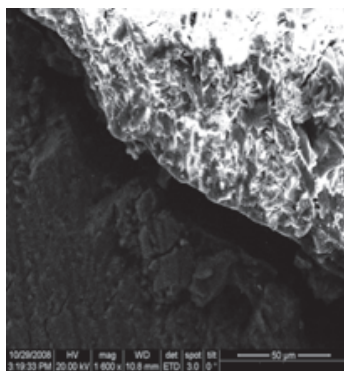

$2 c \quad x 1600$

Fig. 15. SEM photomicrographs of dentin surface treated with Bis-GMA2 based adhesive and Bis-GMA2 based composite 


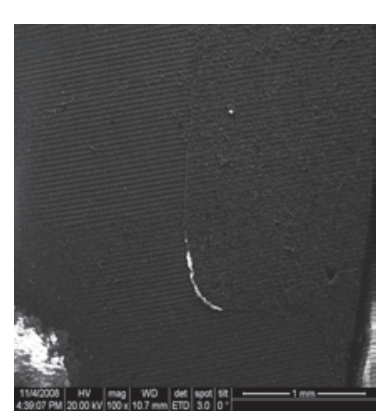

3a $\quad \times 100$

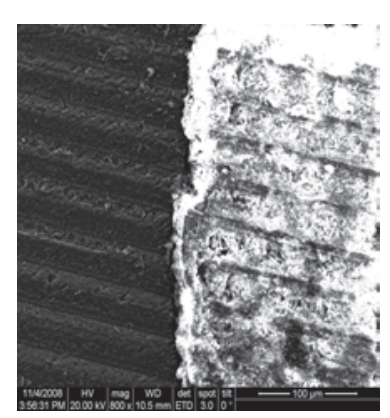

$3 b \quad x 800$

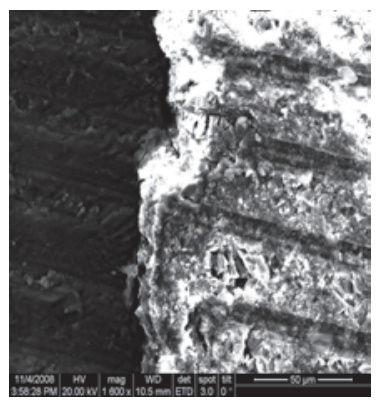

$3 c \quad \times 1600$

Fig. 16. SEM photomicrographs of dentin surface treated with Bis-GMA0 based adhesive and Bis-GMA0 based composite

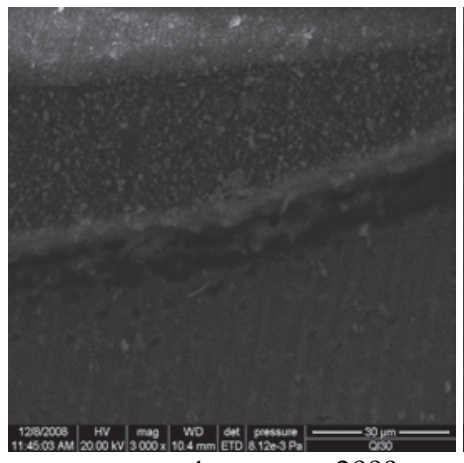

$4 a$

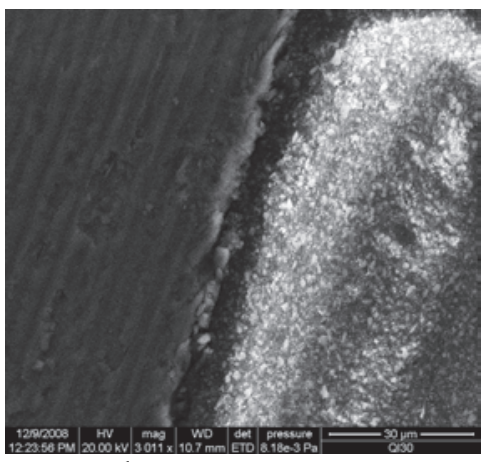

$4 b \quad x 3000$

Fig. 17. SEM photomicrographs of dentin surface treated with Optibond FL adhesive system and Herculite composite

\section{Conclusions}

Within the limits of our experiments, we came to the following conclusions.

Among the experimental Bis-GMA type oligomers, Bis-GMA2 leads to the obtaining of composites with highest compressive and flexural strengths and the lowest value for water sorption. The values obtained for polymerization shrinkage show that the resin based on Bis-GMA1 monomer has a polymerization shrinkage that represents $2 / 3$ of the value presented by commercial Bis-GMA-based resin. This behavior can be correlated with the good adhesion to tooth tissues that was obtained in the case of using the adhesive system and the light curing composite based on Bis-GMA1 monomer. The polymerizable lightstabilizer Cyasorb UV 2098 was more effective in time than the conventional low molecular weight stabilizer Chimasorb 81. Further studies are needed to prepare resins with different Bis-GMA1/Bis-GMA2/TEGDMA ratio and different filler loading in order to obtain dental materials with optimum performance. 


\section{Acknowledgments}

This work was supported by Romanian National Project PNCDI2 No. 72168/2008 (FLORODENT), Parteneriate Program .TGN dedicates her contribution to the memory of Prof. S. Kalachandra, an unforgettable friend and colleague.

\section{References}

Asmussen, E. (1982). Factors affecting the quantity of remaining double bonds in restorative resin polymers. Scand J Dent Res,Vol. 90, No. 6, pp. 490-496, ISSN 0029-845X

Bowen R. L., (1962). U. S. Patent, 3.066.112.

Bowen R. L., Marjenhoff W. A. (1992). Dental Composites/Glass Ionomers: The Materials. Adv Dent Res, Vol. 6, pp. 44-49, ISSN 2229-4112

Buruiana, T., Buruiana E. C., Melinte V., Pohoata V., Prejmerean C., Moldovan M. (2008). Newurethane dimethacrylates fortesting in dental applications. J. Optoelectron. Adv. Mater., Vol. 10, No. 4, pp. 969-974, ISSN 1454-4164

Cara R.R., Nicola C., Prejmerean C., Sava S., Baciut G., Baciut M., Bran S., Bondor C., Prodan D., Moldovan M., Buruiana T., Patrascu I. (2010). Influence of Bis-GMA Derivative Monomer-Based Particulate Composite Resins on the Cuspal Deformation and Microleakage of Restored Teeth. Particulate Science and Technology, Vol. 28, pp. 191-206, Publisher Taylor \&Francis, ISSN 0272-6351

Causton, B. E., Miller B., Sefton J. (1985). The deformation of cusps by bonded posterior composite restorations: An in vitro study. Br. Dent. J., Vol. 159, pp. 397-400, ISSN 0007-0610

Davidson, C. L., Feilzer A. J. (1997). Polymerisation shrinkage and polymerisation shrinkage stress in polymer-based restoratives. J Dent., Vol. 25, pp. 435-440, ISSN 0300-5712

Davidson, C. L., De Gee A. J., Feilzer A. J. (1984). The competition between the compositedentin bond strength and the polymerization contraction stress. J Dent Res, Vol. 63, No. 12, pp. 1396-1399, ISSN 0022-0345

Ferracane JL. (1994.) Elution of leachable components from composites. J. Oral Rehabil 1994; 21: 441-452, ISSN 0305-182X

Freilich, M.A., Meiers, J. C., Duncan, J. P., Goldberg, A. J. (2000). Fiber-reinforced composites in clinical dentistry, Quintessence Pub. Co., ISBN 0867153733

Grassie N. (1966). Degradation, In : Encyclopedia of polymer science and technology, Mark HF, Gaylord NG, Bikales NM, vol. 4. pp. 647-716, John Wiley \& Sons Inc., ISBN 10 0470569700, New York

Holter, D., Frey H., Mulhaupt R., (1997). Branched bismethacrylates based on Bis- GMA-A systematic route to low shrinkage composites. Polym. Preprints, Vol. 38, No.2, pp. 84-85, ISSN 0032-3934

Jorgensen, K. D., Asmussen, E., Shimokobe, H.. (1975). Enamel damages caused by contracting restorative resins. Scand J Dent Res. Vol. 83, pp. 120-122, ISSN 0029-845X

Kemp-Scholte, C.M., Davidson C.L. (1990). Marginal integrity related to bond strength and strain capacity of composite resin restorative systems. J.Prosthet. Dent., Vol. 64, pp. 658-664, ISSN 0022-3913.

Khatria, C.A., Stansbury J. W., Schultheisz C. R., Antonucci J. M. (2003). Synthesis, characterization and evaluation of urethane derivatives of Bis-GMA. Dent. Mater. , Vol. 19, No.17, pp. 584-588, ISSN: 0109-5641 
Letzel, H. (1989). Survival rates and reasons for failure of posterior composite restorations in multicentre clinical trial. J. Dent. Vol. 17, pp. 10-17, ISSN: 0300-5712

Mozner N., Salz U. (2001). New developments of polymeric dental composites. Prog. Polym. Sci., 26, pp. 535-576, ISSN 0079-6700.

Moszner, N., U. K. Fischer, J. Angermann, and V. Rheinberger. (2008). A partially aromatic urethane dimethacrylate as a newsubstitute for Bis-GMA in restorative composites. Dent. Mater. 24: 694-699, ISSN: 0109-5641

Nunes, T.G., Pires, R., Perdigão, J., Amorim, A, Polido, M. , (2001). Polymer, Vol. 42, pp. 8051-8054, ISSN 0032-3861

Nunes, T.G., Guillot, G., Pereira, S.G., Pires, R. (2002). Journal of Physics D-Applied Physics; Vol. 35, No.11, pp.1251-1257, ISSN0022-3727.

Nunes T.G., Ceballos L., Osorio R., Toledano M. (2005). Spatially-Resolved Photopolymerization Kinetics and Oxygen Inhibition in Dental Adhesives, Biomaterials, Vol. 26, No. 14, pp. 1809, ISSN 0142-9612

Nunes T. G., Pereira S.G. , Kalachandra S. (2008). Effect of Treated Filler Loading on Dental Resin Photopolymerization Inhibition and Contraction, J. Materials Science: Materials in Medicine, Vol. 19, pp. 1881-1889, ISSN: 0957-4530

Pereira S.G., Reis N., Nunes T.G. (2005). Spatially resolved studies on the photopolymerization of dimethacrylate monomers, Polymer, Vol. 46, pp. 8034-8044, ISSN 0032-3861

Pereira, S. G., Nunes T. G., Kalachandra S. (2002). Low viscosity dimethacrylate comonomer composition [Bis-GMA and $\mathrm{CH} 3$ Bis-GMA] for novel dental composites, Biomaterials Vol. 23, pp. 3799-3806, ISSN 0142-9612

Pereira S.G., Osorio R, Cabrerizo-Vilchez, M.A., Toledano, M., Nunes T.G., Kalachandra, S., (2007). Dent Mater, Vol. 23, No.10, pp. 1189-1198, ISSN: 0109-5641

Peutzfeld, A. (1997). Resin composites in dentistry: The monomer systems, Eur. J. Oral Sci., Vol. 105, pp. 97-116, ISSN 0909-8836

Prejmerean, C., Vezsenyi, M., Moldovan, M., Grecu, R., Musat, O., Brie, M., (2000). The synthesis of Bis-GMA oligomers and their effects upon the properties of some experimental dental composites, Rev Roum Chim, Vol. 45, No 6, pp. 567-577, ISSN 0035-3930

Ruyter, I.E., Gyorosi P.P., (1976). An infrared spectroscopic study of sealants, Scand J Dent Res, Vol. 84 pp.396-400, ISSN0029-845X 


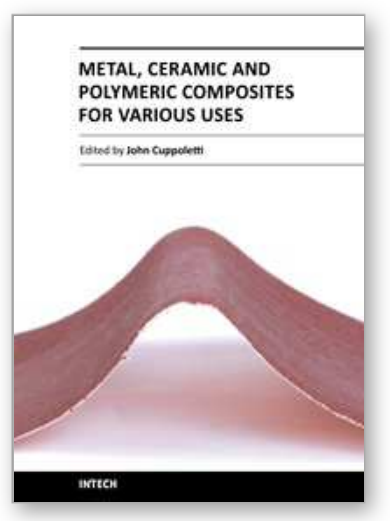

\author{
Metal, Ceramic and Polymeric Composites for Various Uses \\ Edited by Dr. John Cuppoletti
}

ISBN 978-953-307-353-8

Hard cover, 684 pages

Publisher InTech

Published online 20, July, 2011

Published in print edition July, 2011

Composite materials, often shortened to composites, are engineered or naturally occurring materials made from two or more constituent materials with significantly different physical or chemical properties which remain separate and distinct at the macroscopic or microscopic scale within the finished structure. The aim of this book is to provide comprehensive reference and text on composite materials and structures. This book will cover aspects of design, production, manufacturing, exploitation and maintenance of composite materials. The scope of the book covers scientific, technological and practical concepts concerning research, development and realization of composites.

\title{
How to reference
}

In order to correctly reference this scholarly work, feel free to copy and paste the following:

Cristina Prejmerean, Tinca Buruiana, Teresa Nunes, Marioara Moldovan and Loredana Colceriu (2011). Biocomposites Based on New Monomer Systems Reinforced with Micro /Nanoparticles and Glass Fibers, Metal, Ceramic and Polymeric Composites for Various Uses, Dr. John Cuppoletti (Ed.), ISBN: 978-953-307353-8, InTech, Available from: http://www.intechopen.com/books/metal-ceramic-and-polymeric-compositesfor-various-uses/biocomposites-based-on-new-monomer-systems-reinforced-with-micro-nanoparticles-andglass-fibers

\section{INTECH}

open science | open minds

\author{
InTech Europe \\ University Campus STeP Ri \\ Slavka Krautzeka 83/A \\ 51000 Rijeka, Croatia \\ Phone: +385 (51) 770447 \\ Fax: $+385(51) 686166$ \\ www.intechopen.com
}

\author{
InTech China \\ Unit 405, Office Block, Hotel Equatorial Shanghai \\ No.65, Yan An Road (West), Shanghai, 200040, China \\ 中国上海市延安西路65号上海国际贵都大饭店办公楼 405 单元 \\ Phone: +86-21-62489820 \\ Fax: +86-21-62489821
}


(C) 2011 The Author(s). Licensee IntechOpen. This chapter is distributed under the terms of the Creative Commons Attribution-NonCommercialShareAlike-3.0 License, which permits use, distribution and reproduction for non-commercial purposes, provided the original is properly cited and derivative works building on this content are distributed under the same license. 